To cite this article: J. PACHÓN-MORALES, P. PERRE, J. CASALINHO, D. SCHOTT, F. PUEL and J. COLIN; (2020) Potential of DEM for investigation of non-consolidated flow of cohesive and elongated biomass particles, Advanced Powder Technology 31, 1500-1515 https://doi.org/10.1016/j.apt.2020.01.023

\title{
Potential of DEM for investigation of non- consolidated flow of cohesive and elongated biomass particles
}

\author{
John Pachón-Morales a1, Patrick Perré a,c, Joel Casalinho a, Huy Do b, Dingena Schott b, François Puel a, \\ Julien Colin a,c \\ aLGPM, CentraleSupélec, Université Paris-Saclay, 3 rue Joliot-Curie, 91192 Gif-sur-Yvette, France \\ bSection Transport Engineering and Logistics, Department Maritime \& Transport Technology, Faculty of \\ Mechanical, Maritime and Materials Engineering, Delft University of Technology, Mekelweg 2, 2628CD Delft, The \\ Netherlands \\ cLGPM, CentraleSupélec, Université Paris-Saclay, SFR Condorcet FR CNRS 3417, Centre Européen de \\ Biotechnologie et de Bioéconomie (CEBB), 3 rue des Rouges Terres, 51110 Pomacle, France
}

\section{ABSTRACT}

The evaluation of the flow properties of biomass powders is essential for the design of handling systems within a thermochemical valorization context. The Discrete Element Method (DEM) is a valuable tool for simulating the bulk behavior of granular materials that has rarely been used for biomass feedstocks. This work focuses on the numerical investigation of the flow of raw and torrefied biomass particles in a loose and dynamic conditioning using a rotating drum. The relevance of DEM parameters calibrated using bulk experiments (angle-of-repose, bulk density, retainment ratio) is tested by comparison with experimental data obtained using a rotating drum system. The calibrated DEM material model considers the elongated, submillimetric and cohesive nature of the biomass powder. Several flowability descriptors (Upper Angle of Stability, size of avalanches, fraction of revolution to trigger events and irregularity of the free surface) are evaluated using both experimental data and DEM simulations. DEM results reproduced well the experimental trends and distinguished between the different cohesive extent of the samples. DEM is therefore a relevant technique for assessing flowability of biomass powders in a non-consolidated dynamic flow. This paves the way for investigating the effects of particle characteristics on bulk flow, which are briefly discussed.

\section{Keywords}

Woody biomass powder; DEM parameter calibration; Flowability; Avalanching; Multisphere approach; Coarse-graining; Particle shape; Rotating drum

${ }^{1}$ Corresponding author:

E-mail adresses : (J. Pachón-Morales) john.pachon@,centralesupelec.fr, J. Colin) julien.colin@,centralesupelec.fr 


\section{INTRODUCTION}

Interest in lignocellulosic biomass has sharply increased recently due to its potential as a renewable energy source to produce chemicals and gaseous or liquid biofuels. In biomass gasification processes for $2^{\text {nd }}$ generation biofuel production, the granular flowability of the biomass feedstock influences the continuous, stable and controllable operation of the gasifier, which affects the design of reactors and composition of the product gas [1-3]. Flow fluctuations, bridging and blockage of biomass particles in feeding systems of gasifiers are common industrial problems that hinder the cost-effective industrialization of biomass valorization facilities.

Before being fed into the gasifier, the biomass can be pre-treated, namely by torrefaction. Torrefaction is a mild pyrolysis at temperatures ranging between $200{ }^{\circ} \mathrm{C}$ and $300{ }^{\circ} \mathrm{C}$ in an inert environment. Details on the effects of torrefaction on biomass properties and its interest as pretreatment step for biomass valorization can be found in [4,5]. In addition to improving the energy density and grindability of the material, torrefaction also influences the size and shape of the particles obtained after grinding [6,7] which has an impact on flow properties.

Flow issues can be correctly addressed through knowledge of the flow behavior of bulk solids. Despite the relatively frequent occurrence of flow problems, little is known about the flow properties of biomass materials, which may differ significantly from those of conventional granular materials used in industry [8]. So far, research on the flow properties of milled biomass has primarily focused on measurements using shear testers [6,9-13] in which powders are in a consolidated and quasi-static state.

Rotating drums are widely used devices for characterizing flowability of powders in a loose and dynamic state. They stand as a very practical geometry to study the flow of granular materials through, for instance, the evaluation of their avalanching behavior. The test does not require an extensive sample preconditioning, is performed quickly and can be repeated many times without operator intervention. In addition, rotating drums can detect changes in powder flowability brought by powder additives with greater precision and reproducibility than other commonly used loose-state tests such as angle-of-repose tests and bulk density measurements [14]. Although an overwhelming majority of work using rotating drums has focused on cohesionless materials [15-18], recent research [18-23] has highlighted the pertinence of the study of avalanches to assess flowability of cohesive materials such as moist pharmaceutical [24] and cocoa [25] powders. The avalanche characterization of biomass powder -which has a recognized cohesive charactercould provide a new insight on the dynamic free-surface flow behavior of this material. For instance, values of the upper angle of stability obtained from rotating drum experiments have been correlated to the discharge rates at the outlet of screw feeders for biomass [12].

With the rapid development of high-performance computing technology, the Discrete Element Method (DEM) [26] is becoming a powerful simulation tool to understand granular dynamics, particularly in rotating drum flows [27]. Experimental evaluation of the isolated effects of shape, size or surface interactions on the flow behavior of bulk solids can be difficult to achieve since these properties are often correlated. Access to the individual particle dynamics of fine materials is also a major difficulty in experimental work. The ability to run a large number of simulations with full control of the physical properties of the system under study makes DEM simulations a cost-effective way to help overcome experimental limitations. It also gives an insight on the particle-scale phenomena taking place during flow.

Two approaches are commonly used in literature to study the flow of granular materials in rotating drums using DEM. First, a large number of investigations focuses on the microdynamics of particles flow within the drum, namely through the assessment of coordination numbers, collision frequencies of individual particles and velocity profiles [28-32]. A second approach includes the evaluation of global bulk characteristics such as dynamic angles of repose or the study of mixing and segregation of polydisperse 
populations [27,30,32-40]. The latter approach was used in this work, since flowability was assessed using bulk flow descriptors based on the motion of the mass center of the powder bed.

Due to limited computing power, implementation of DEM has limitations for simulating full-scale industrial applications, where large quantities of particles are involved [41]. Non-spherical particle shapes as well as cohesive behavior are also expensive features to model in DEM, mainly due to the need for more complex contact detection algorithms and force models. In consequence, so far, most numerical studies on granular flow in rotating drums are restricted to either spherical, non-cohesive or coarse $\left(d_{p}>1 \mathrm{~cm}\right)$ materials. However, challenging aspects of modelling biomass particles are precisely the inclusion of a realistic shape model, along with a cohesive behavior for low-particle-density and submillimetric particles.

The effects of particle shape on the flow behavior of non-cohesive granular materials inside rotating drum setups, using both DEM and experimental approaches, have been the subject of recent research [32,34-37,39,40,42-45]. For instance, Norouzi et al. [34] numerically studied the flow behavior of both spherical and non-spherical cohesionless polystyrene particles. They found that, at the same operating conditions (namely, rotational speed and filling ratio), the dynamic angle of repose -defined as the angle between the flat surface of particles and the horizontal axis- was greater for non-spherical than for spherical particles. Similar conclusions were drawn by Santos et al. [32] for rice grains compared to spherical glass beads. Mead et al. [36] comprehensively studied the influence of the aspect ratio, angularity, particle size distribution and inter-particle contact friction on the angle of repose obtained using a rotating cylinder in an avalanching regime. Wachs et al. [42] and Höhner et al. [39] have conducted DEM simulations of spheres and three different polyhedral particles in a rotating drum. They have found that the dynamic angle of repose increased with decreasing particle sphericity. Additionally, angular particles led to a less flat free surface of the particle bed and an intermittent flow behavior.

Unlike non-cohesive free-flowing materials, cohesive flow in rotating drums has been investigated far less. Granular cohesive systems may exhibit very different flow patterns and physical behavior (e. g. avalanching) than systems where cohesion is not significant [20,46]. Prior studies on DEM simulation of cohesive bulk materials in rotating drums include the study of velocity profiles [47], avalanching and surface angles $[20,38,47]$, segregation and axial dispersion $[46,48]$. Brewster et al. [47] have reported that the magnitude of interparticle cohesion has a significant effect on the shape of the powder free surface. At low rotation rates and high enough interparticle cohesion, the powder free surface is convex. Decreasing the cohesion or increasing the rotation rate causes the free surface to flatten. Using DEM simulations Faqih et al. [49] have shown that the cohesion of the material is directly proportional to the standard deviation of the center of mass of a powder inside a rotating drum.

To obtain results that accurately reproduce experimental behavior, DEM parameters must be carefully chosen, measured or adjusted through calibration. Prior studies have used results from rotating drum experiments, predominantly the dynamic angle of repose, for DEM calibration of non-cohesive materials $[32,50,51]$. However, reaching a steady state may need several rotations of the drum, which requires long computation times, especially for a large number of submillimetric particles. Since calibration procedures generally involve running several batches of simulations with combined DEM parameters, the entire process would result in impractical timeframes. A first attempt for accelerating DEM calibration using rotating drum results was made by $\mathrm{Hu}$ et al. [27], by using the critical upper and lower angles of the first avalanche. This approach has yielded satisfactory results for spherical and non-cohesive materials. However, in the case of elongated and cohesive powders, the highly chaotic and history-dependent nature of the avalanches requires an assessment of dynamics over a long period of time.

As previously commented, in addition to the calibration of DEM parameters, the large number of particles of typical industrial processes is another factor that limits the use of DEM in industry [52]. Scaling up particle size is one technique that allows simulations to be run in a reasonable period. Coetzee [40] studied 
the effect of using upscaled particles on the dynamic angle of repose of corn grains in a rotating drum and identified a single set of calibrated parameters for all particles with scaling factors ranging from 1.0 to 4.0. Several particle scaling approaches have been proposed in literature, including exact scaling $[41,53]$, coarse graining $[54,55]$ and cutting-off approach [56]. A coarse-graining approach reduces computational effort by replacing individual (real) particles by representative upscaled 'meso'-particles $[55,57,58]$. This approach has shown promising results for simulation of submillimetric biomass particles [59].

This paper presents a numerical study on the macroscopic flow behavior of raw and torrefied biomass powders in a rotating drum setup using DEM. Comparison with experimental data makes it possible to assess the relevance of DEM parameters calibration from bulk experiments, applied to a rotating drum system. Several avenues of novelty are covered in this work. First, the application of DEM and its calibration for modeling flow of a cohesive, non-spherical material that has been very rarely treated in the literature so far. Secondly, this work illustrates the use of a calibration procedure using simple and fast-to-obtain results to realistically represent biomass flow in a rotating geometry. By using raw and torrefied powders with different particle characteristics (size, shape and cohesiveness) we evaluated the ability of the calibration parameters to express different flow behaviors and set a flowability classification.

The results are intended to be useful in understanding the effect of particle size, shape and interparticle forces on the flowability of biomass powders in a non-consolidated and dynamic regime.

First, the material characteristics and the experimental setup are presented in the materials and method section. Thereafter, the DEM simulation methodology is detailed. Several relevant flowability descriptors such as the Upper Angle of Stability, the avalanche size, the fraction of revolution to trigger events and the irregularity of the free surface are evaluated from experimental data and DEM simulations. A comparison is made and comments on the effects of particle characteristics on flow behavior are finally provided.

\section{Granular materials and experimental setup}

\subsection{Granular material preparation}

Poplar (Populus euro-americana Koster) was used in this study as representative of a fast-growing lignocellulosic crop. A poplar tree was cut into boards that were then dried. Samples of $60 \times 80 \times 15 \mathrm{~mm}^{3}$ were cut from a selected board.

The coupled effect of torrefaction and sieving on particle characteristics was considered in this work. Torrefaction was made in a batch furnace especially developed to assure homogeneous inter-particle treatment [60]. A controlled inert atmosphere, swept by a nitrogen flow, guaranteed an oxygen level below $1.5 \%$. Two treatments were performed at $240{ }^{\circ} \mathrm{C}$ and $280^{\circ} \mathrm{C}$ for 1 hour according to the following protocol: (i) heating from room temperature to $100{ }^{\circ} \mathrm{C}$ at a rate of $10^{\circ} \mathrm{C} \cdot \mathrm{min}^{-1}$ (ii) plateau at $100{ }^{\circ} \mathrm{C}$ for 12 hours to remove bound residual water (iii) heating at a rate of $10^{\circ} \mathrm{C} \cdot \mathrm{min}^{-1}$ to the treatment temperature (iv) plateau at the treatment temperature for 1 hour and (v) cooling ensured by thermal losses and increased nitrogen flow into the reactor.

The oven-dried mass of the samples before $\left(m_{0}\right)$ and after $\left(m_{t}\right)$ torrefaction was measured to calculate the mass loss $(M L)$ due to heat treatment:

$$
\text { ML }(\%)=\frac{m_{0}-m_{t}}{m_{0}} \cdot 100
$$

The mass loss is known to be a good indicator of the torrefaction intensity and has been successfully correlated to several properties of the treated biomass such as dimensional changes [61], energy properties 
[62], and flowability [6,63]. Mass losses of $9.6 \pm 0.8 \%$ and $24.5 \pm 3 \%$ were obtained for the samples torrefied at $240{ }^{\circ} \mathrm{C}$ and $280^{\circ} \mathrm{C}$, respectively.

The biomass samples (raw and treated) were ground using a Retsch SM300 knife mill with a 1-mm trapezoidal hole bottom sieve at the outlet. Although an outlet sieve was used during grinding, the powders obtained were still quite polydisperse and had many fine particles. The timestep for DEM simulations of strongly polydispersed systems should be reduced according to the smallest particle present, which, in the case of biomass samples, would lead to impractical simulation times [64]. Therefore, the powders obtained after grinding were sieved to reduce polydispersity in particle size and shape. A Retsch AS 200 vibratory sieve shaker at an amplitude of $60 \%$ (1.8 mm) for 20 minutes was used along with sieves of opening $500 \mu \mathrm{m}$ and $710 \mu \mathrm{m}$. Particle size and shape distributions were obtained using a Sympatec-QICPIC morphological particle size analyzer [65]. The main descriptors of the distributions are listed in Table 1.

For comparative purposes, $1-\mathrm{mm}$ diameter glass beads were used as representative of materials with spherical and non-cohesive particles. The SEM images presented in Figure 1 depict the elongated shape of biomass particles compared to glass beads. It is noteworthy that, despite the sieving stage, the average particle size (minimum Feret diameter) decreased with the intensity of torrefaction. The aspect ratio values reveal that intensively torrefied samples were also less elongated than the raw and the mildly torrefied ones, which is likely to influence their flow properties as discussed in [66].

Table 1. Sample size and shape characteristics.

\begin{tabular}{|c|c|c|c|c|c|c|c|c|}
\hline Sample & $\begin{array}{l}\text { Torrefaction } \\
\text { temperature }\end{array}$ & $\begin{array}{l}M L \\
(\%)\end{array}$ & $\begin{array}{c}\text { Sieving } \\
\text { cut } \\
(\mu \mathrm{m})\end{array}$ & $\begin{array}{c}d_{50^{*}} \\
(\mu \mathrm{m})\end{array}$ & $\begin{array}{c}d_{90} \\
(\mu \mathrm{m})\end{array}$ & $\begin{array}{c}d_{10} \\
(\mu \mathrm{m})\end{array}$ & $S_{d}$ & $a_{50}$ \\
\hline Glass beads & ---- & ---- & $\begin{array}{ll}--- \\
\end{array}$ & 1212 & 1373 & 1051 & 0.13 & 0.99 \\
\hline $\begin{array}{c}\text { Raw biomass } \\
\text { Mildly }\end{array}$ & Untreated & 0 & $500-710$ & 746 & 1092 & 519 & 0.36 & 0.38 \\
\hline $\begin{array}{l}\text { torrefied } \\
\text { biomass }\end{array}$ & $240^{\circ} \mathrm{C}$ & 9.6 & $500-710$ & 667 & 929 & 448 & 0.35 & 0.31 \\
\hline $\begin{array}{c}\text { Intensively } \\
\text { torrefied } \\
\text { biomass }\end{array}$ & $280^{\circ} \mathrm{C}$ & 24.5 & $500-710$ & 526 & 862 & 303 & 0.48 & 0.41 \\
\hline
\end{tabular}
the aspect ratio distributions ( $a=$ minimum Feret diameter/maximum Feret diameter)

(a) Glass beads

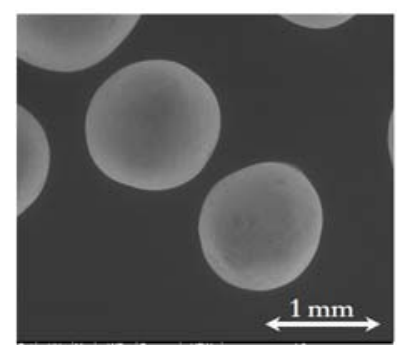

(b) Raw biomass

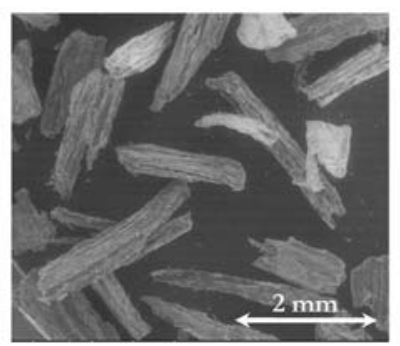

(c) Torrefied biomass $M L=9.4 \%$

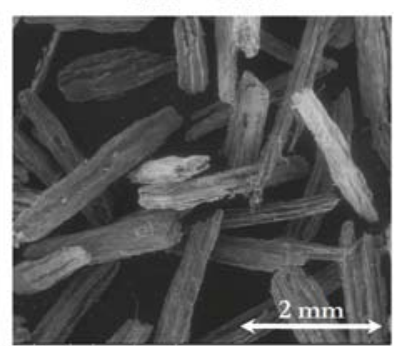

(d) Torrefied biomass $M L=24.5 \%$

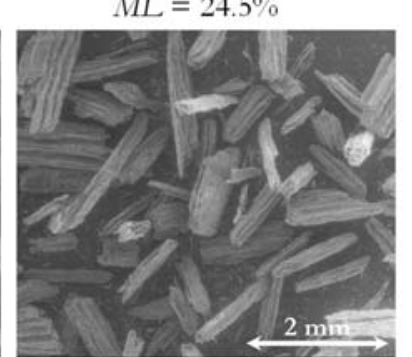

Figure 1. Typical SEM images of the granular materials used in this work.

\subsection{Rotating drum and avalanching tests}

An in-house-designed device was used to evaluate the dynamic flow behavior of the granular materials (Figure 2). When studying avalanching behavior in rotating drums, it is crucial to ensure the absence of external perturbations that would perturb the regular motion of powders or alter their dynamic stability. Such a problem has already been encountered in previous research [67]. Keeping this constraint in mind, an 
in-house experimental device was developed to characterize the dynamics of avalanches over a relatively wide range of rotational speeds. Our device was designed to fulfill several constraints:

- Smooth and regular rotation avoiding any perturbation of the intrinsic powder behavior,

- Quality of lightning allowing a high shutter speed and a rigorous and easy post-processing of images,

- Drainage of electrical charges to reduce electrostatic forces effects,

- Suitable range of rotational speeds

The core piece of this device a stainless-steel cylinder $(10 \mathrm{~cm}$ inner diameter, $2 \mathrm{~cm}$ width, roughness Ra $\approx 0.4 \mu \mathrm{m}$ ) clamped inside a roller bearing (IKO NAG 4924UU) as shown in Figure 2a-b. This design is the key-feature of our in-house device: it ensures a regular and smooth rotation, without vibrations and permits the uniform lighting required to grab high quality images. Two transparent conductive ITO (Indium-Tin oxide)-coated glass discs are used to ensure the drainage of static electricity. The drive mechanism, built between a motor (maxon RE040G/PM52) and the cylinder housing, deserves also attention. The transmission is made through two pulleys (one changeable) connected by a toothed belt. This configuration ensures a steady and stable rotational speed that can range between $0.01 \mathrm{rpm}$ and $73 \mathrm{rpm}$ for the chosen pulley-belt set.

In order to observe and record powder motion, an optical montage ensuring axial alignment between the camera and the drum was built. Images were acquired using a Photron FASTCAM high-speed camera (Mini AX100, max. resolution $1024 \times 1024$ pixels, max. framerate $4000 \mathrm{fps}$ ) along with a $105 \mathrm{~mm} \mathrm{f} 2.8 \mathrm{EX}$ DG Macro OS SIGMA lens. A framerate of 50 fps during $1065 \mathrm{~s}$ with a resolution of $896 \times 720$ pixels was used. This configuration allows a relatively high exposure time $(1 / 30000 \mathrm{~s})$ while taking clear images even during the avalanche motion. The camera was positioned horizontally facing the frontal side of the drum, with the center of view being aligned with the drum axis. A LED lighting panel (HSC PHLOX $24 \mathrm{~V}$ ) was fixed behind the drum to obtain high-contrast shadow images of the powder.

A volume of $63 \mathrm{~cm}^{3}$ of oven-dried materials was charged into the drum, corresponding to a filling ratio of $40 \%$. All the tests were performed at ambient relative humidity between $46 \%$ and $55 \%$ and at a rotational speed of $0.5 \mathrm{rpm}$. To automatically process the large set of images of each test (typically ca. 18.000 images per test), a post-processing procedure was implemented using the Image Processing Toolbox ${ }^{\mathrm{TM}}$ of MATLAB platform.

Powder motion inside the drum was followed using the 'centroid angle' $(\alpha)$ defined as the angle between the horizontal and the line from center of the drum to the center of mass of the powder bed (Figure 2c). This indicator has been found relevant for the experimental evaluation of the flowability of cohesive materials using a rotating drum [25].

Three flow parameters were extracted from the temporal evolution of $\alpha$. The first one is the Upper Angle of Stability (UAS), which is defined as the maximum value of $\alpha$ before an event (or 'avalanche'). $U A S$ is an indicator of the inter-particle frictional forces that particles must overcome to slide across over each other or to detach from the main bed to create an avalanche. Higher $U A S$ values and wider $U A S$ distributions generally correspond to a decreased flowability. The second one is the size of avalanches, that corresponds to the $\alpha$ variation during an event. Large avalanches in cohesive materials are generally an indicator of poor flowability, as particles tend to form large clumps that break off and collapse over the powder surface. Finally, the third parameter is the fraction of revolution needed to trigger events $(f)$, defined as $f=\omega T / 60 \cdot 100 \%$, where $T$ is the time (s) between events and $\omega$ is the rotational speed (rpm). A greater value of $f$ normally indicates a greater powder cohesion since the events are less frequent. On the contrary, powders having small values of $f$-distributions should flow freely and require lower energy to trigger flow [19] . The determination coefficient $\left(r^{2}\right)$ was also calculated as an indicator of the smoothness of the freesurface profile of the powders. This coefficient evaluates the goodness of fit of a linear regression to the 
surface profile. Cohesive materials tend to form agglomerates when tumbling, so their surfaces are expected to be rough and irregular, resulting in values of $r^{2}$ much less than the unit.

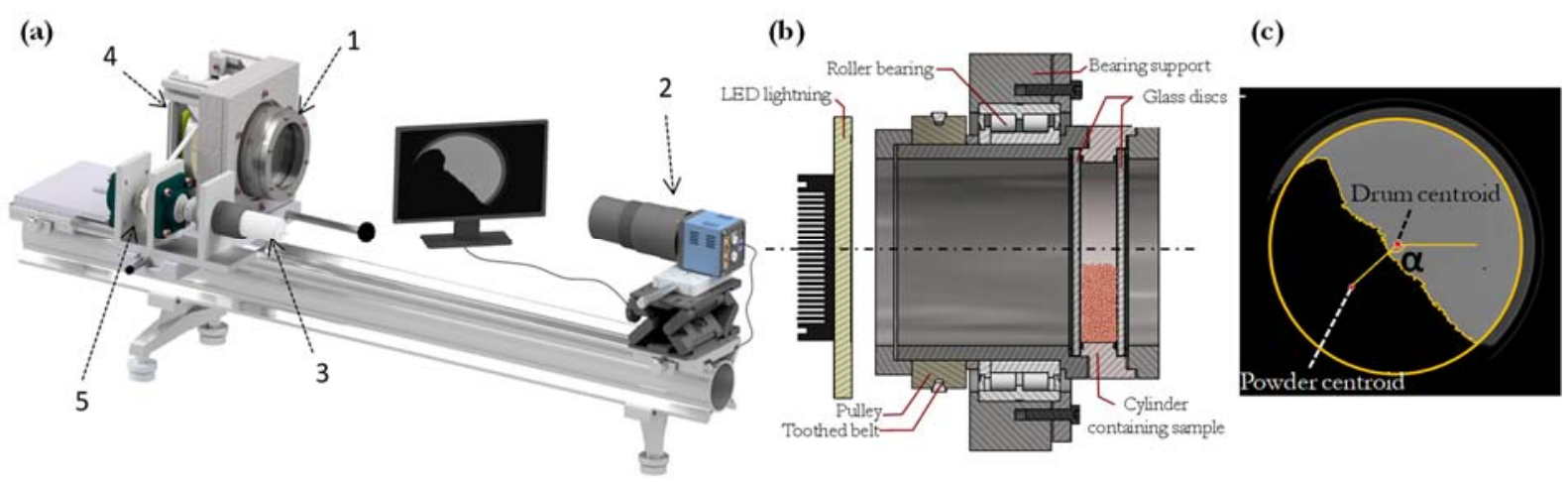

Figure 2. Rotating drum system. (a) Experimental setup: 1: rotating cylinder, 2: high-speed camera, 3: motor, 4: lighting panel, 5. drive system, (b) detail on the cylinder (c) Centroid angle ( $\alpha$ ) definition

\section{DEM modelling}

This section starts with an overview of the DEM contact model used in this work and the procedure for representing particle size and shape using a coarse-grained multisphere approach. Then, the methodology for calibrating the DEM parameters is briefly explained and finally the geometry of the simulated rotating drum is presented.

\subsection{Contact model}

Simulations were conducted using the public version of LIGGGHTS 3.8.0 DEM code [68], parallelized on a E5-2620 v4 $2.10 \mathrm{GHz}$ Intel ${ }^{\circledR} \mathrm{Xeon}^{\circledR}$ machine with $125.8 \mathrm{~GB}$ of RAM. A classic non-linear springdashpot model of Hertz-Mindlin was used as the basic contact model for all samples. For biomass samples, an elastic-plastic spring-dashpot (EPSD2) rolling friction model and a simplified Johnson-Kendall-Roberts (SJKR) cohesion model were also included.

The Hertz-Mindlin model stands as the most commonly used contact model due to its efficient and accurate force calculations. At any time $t$, the equations governing the translational and rotational motion of particle $i$ of mass $m_{i}$ and radius $R_{i}$ can be written as:

$$
m_{i} \frac{d \mathbf{v}_{i}}{d t}=\Sigma_{j}\left(\mathbf{F}_{i j}^{e}+\mathbf{F}_{i j}^{d}+\mathbf{F}_{i j}^{\omega b}\right)+m_{i} \mathbf{g}
$$

and

$$
I_{i} \frac{d \omega_{i}}{d t}=\Sigma_{j}\left(\mathbf{T}_{i j}^{t}+\mathbf{T}_{i j}^{r}\right)
$$

where $\mathbf{v}_{\mathbf{i}}$ and $\omega_{\mathrm{i}}$ are the translational and rotational velocities of particle $i . m_{i}$ and $I_{i}$ are the mass and the moment of inertia of the particle. The indices $i$ and $j$ can also represent particle-wall interactions. The forces involved are: the gravitational force $m \mathbf{g}$ and the forces between particles which include an elastic force $\mathbf{F}_{i j}$ , a viscous damping component $\mathbf{F}_{i j}^{d}$ and cohesive contributions (for biomass samples) through the $\mathbf{F}_{i j}^{\text {cob }}$ term. The torque acting on particle $i$ due to particle $j$ includes two components: $\mathbf{T}_{i j}^{t}$ which is generated by the tangential force and causes particle $i$ to rotate, and $\mathbf{T}_{i j}^{r}$, the rolling friction torque generated by asymmetric distribution of the normal contact force and slows down the relative rotation between particles in contact $[69,70]$. If particle $i$ undergoes multiple interactions, the individual interaction forces and torques 
sum up for all particles interacting with particle $i$. The equations for calculation of each force contribution are reported in Table 2. A complete description of the elasto-plastic spring-dashpot rolling friction model EPSD2 is given in [71].

Table 2. Equations for calculations of forces and torques on particle $i$ according to the Hertz-Mindlin model.

\begin{tabular}{|c|c|}
\hline Force or torque contribution & Equation \\
\hline Normal elastic force, $\mathbf{F}_{i j, n}^{e}$ & $k_{n} \boldsymbol{\delta}_{i j, n}=-4 / 3 Y_{e f f} \sqrt{\mathrm{R}_{e f f}} \boldsymbol{\delta}_{i j, n}{ }^{3 / 2}$ \\
\hline Normal damping force, $\mathbf{F}_{i, n}^{d}$ & $\gamma_{n} \mathbf{v}_{i j, n}=-\frac{2 \sqrt{5 / 6} \ln (\mathrm{e})}{\sqrt{\ln ^{2}(\mathrm{e})+\pi^{2}}} \sqrt{2 Y_{e f f}\left(\mathrm{R}_{e f f} \delta_{i j, n}\right)^{1 / 2} m_{e f f}} \mathbf{v}_{i j, n}$ \\
\hline Tangential elastic force, $\mathbf{F}_{i j, t}^{e}$ & $k_{t} \boldsymbol{\delta}_{i j, t}=-8 G_{e f f} \sqrt{R_{e f f} \delta_{i j, n}} \boldsymbol{\delta}_{i j, t}$ \\
\hline Tangential damping force, $\mathbf{F}_{i j, t}^{d}$ & $\gamma_{t} \mathbf{v}_{i j, t}=-\frac{2 \sqrt{5 / 6} \ln (e)}{\sqrt{\ln ^{2}(e)+\pi^{2}}} \sqrt{8 G_{e f f}\left(R_{e f f} \delta_{i j, n}\right)^{1 / 2} m_{e f f}} \mathbf{v}_{i j, t}$ \\
\hline Coulomb friction limit & $\boldsymbol{\delta}_{i j, t}$ truncated to satisfy $\mathbf{F}_{i j, t}^{e} \leq \mu_{s}\left|\mathbf{F}_{i j, n}^{e}+\mathbf{F}_{i j, n}^{d}+\mathbf{F}_{i j, n}^{w b}\right|$ \\
\hline Torque by tangential forces, $\mathbf{T}_{i j}^{t}$ & $\mathbf{R}_{i j} \times\left(\mathbf{F}_{i j, t}^{e}+\mathbf{F}_{i j, t}^{d}\right)$ \\
\hline Torque by rolling friction, $\mathbf{T}_{i j}^{r}$ & EPSD2 model \\
\hline
\end{tabular}

where $1 / m_{\text {eff }}=1 / m_{i}+1 / m_{j}, \quad 1 / R_{\text {eff }}=1 / R_{i}+1 / R_{j}, \quad 1 / Y_{\text {eff }}=\left(1-v_{i}^{2}\right) / Y_{i}+\left(1-v_{j}^{2}\right) / Y_{j}, \quad 1 / G_{\text {eff }}=2\left(2-v_{i}\right)\left(1+v_{i}\right) / Y_{i}+2\left(2-v_{j}\right)\left(1+v_{j}\right) / Y_{j}, \quad \mathbf{R}_{i j}=R_{i}\left(\mathbf{r}_{j}-\mathbf{r}_{i}\right) /\left(R_{i}+R_{j}\right)$, e : coefficient of restitution, $Y$ : Young's modulus, $G$ : shear modulus, $v$ : Poisson's ratio.

Cohesive force models in DEM include the Johnson, Kendall and Roberts (JKR) model [72], the recently developed Parallel Bond Contact Model [73] and Adhesive Elasto-Plastic Contact Models [74]. The simplified formulation of the widely-used Johnson-Kendall-Roberts model (sJKR) [75] was used in this work, for several reasons: (i) because of its availability in LIGGGHTS, (ii) the need for a single calibration parameter and (iii) the successful description of low-stress cohesive material flows that has been observed in previous research [46,59]. This model adds an additional normal force $\mathbf{F}_{i j, n}^{c o h}$ tending to maintain the contact between two particles, given by:

$$
\mathbf{F}_{\mathrm{ij}, n}^{\infty \omega \infty}=C E D \cdot A
$$

where $C E D$ is the Cohesive Energy Density in $\mathrm{J} / \mathrm{m}^{3}$ and $A$ is the contact area between particles, calculated as:

$$
A=\frac{\pi}{4} \frac{\left(d_{i j}-R_{i}-R_{j}\right)\left(d_{i j}+R_{i}-R_{j}\right)\left(d_{i j}-R_{i}+R_{j}\right)\left(d_{i j}+R_{i}+R_{j}\right)}{d_{i j}{ }^{2}}
$$

where $d_{i j}$ is the distance between the center of the particles and $R_{i}, R_{j}$ are the radii of the spheres $i$ and $j$ in contact. For a particle (i)-wall (j) contact, the contact area becomes:

$$
A=\pi\left(R_{i}^{2}-d_{i j}^{2}\right)
$$

\subsection{Particle shape approximation}

To simulate the elongated shape of the biomass particles, a multi-sphere approach was used [76]. Indeed, since spherical shapes facilitate computationally-efficient contact detection, the multi-sphere method is one of the most widely used approach for representing particle shape in DEM [45,77]. Spheres within a multisphere cluster are fixed in position relative to each other and may overlap to approximate more closely to the actual particle shape [76]. Multi-sphere representations have previously been used for describing flow of submillimetric biomass particles [59], wood chips [78] and agricultural resources such as maize and rice grains $[79,80]$. 
Each sample was simulated as a monodisperse population of multi-sphere clusters. High-quality approximations of particle shape using a multisphere approach may require a large number of spheres, making simulations very demanding in memory and computation time. To reduce the number of spheres required to represent a single particle, the individual spheres were oriented on a single longitudinal axis, so that the particles were needle-shaped (Figure 3). To approximate the actual morphology obtained by the PSD measurements, a simplified model of particle representation was proposed. In this model, the number of spheres in a clump, $n_{s p h}$, is function of the particle mean size $\left(d_{50}\right)$, the average aspect ratio $\left(a_{50}\right)$ (Table 1$)$ and an overlapping factor $c$.

The overlapping factor is defined as $c=\lambda / d_{50}$, where $\lambda$ is the overlapping distance between adjacent spheres in $\mu \mathrm{m}$ (Figure 3a). A value of $c=0$ means that two spheres touch at one single point and $c=1$ represents a total overlap between two contiguous spheres. As $c$ increases, the effective roughness of the particle decreases. Previous work [77] has suggested that reducing surface roughness by increasing the number of spheres per cluster does not necessarily lead to a better approximation of particle behavior. A value of $c$ of $20 \%$ was chosen as it is considered a good trade-off between the accuracy of particle representation and the number of spheres required.

The diameter of each sphere is set to be equal to the median minimum Feret diameter of the population, $d_{50}$. Therefore, the length of the clump $\left(l_{\text {clump }}\right)$, which corresponds to the average maximum Feret diameter, can be calculated as follows:

$$
l_{\text {clump }}=d_{50} / a_{50}=n_{s p h} \times\left(d_{50}-\lambda\right)+\lambda
$$

So, from the definitions of $a_{50}$ and $c$, the number of spheres needed per clump is:

$$
n_{s p h}=\frac{1 / a_{50}-c}{1-c}
$$

The calculated values were rounded to the closest integer and the length of the clump was recalculated accordingly.

The volume of each clump is given by:

$$
V_{\text {clump }}=n_{s p h} \pi\left(\frac{d_{50}}{2}\right)^{3}\left(\frac{4}{3}-\frac{n_{s p h}-1}{12 n_{s p h}}(6-2 c)\left(4 c^{2}\right)\right)
$$

Table 3 shows the multisphere model parameters that define each sample. For the sake of comparison with spherical models for particle representation, the equivalent diameter of a sphere having the same volume as one individual clump $\left(d_{e q}\right)$ is also reported. Figure $3 \mathrm{~b}$ presents the multisphere model of

\begin{tabular}{|c|c|c|c|}
\hline & Raw & $M L=9.6 \%$ & $M L=24.5 \%$ \\
\hline$n_{s p h}$ & 3 & 4 & 3 \\
\hline$l_{\text {clump }}(\mu \mathrm{m})$ & 1940 & 2273 & 1367 \\
\hline$V_{\text {clump }}\left(\mathrm{mm}^{3}\right)$ & 0.6282 & 0.5997 & 0.2199 \\
\hline$d_{e q}(\mu \mathrm{m})$ & 1062 & 1046 & 748 \\
\hline
\end{tabular}
each sample used in this investigation.

Table 3. Characteristics of the multisphere model for representation of biomass particles (non-scaled). 
(a)

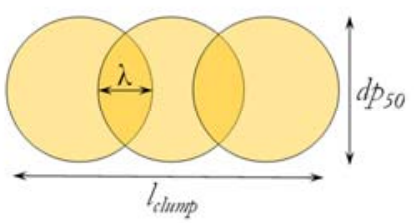

(b)

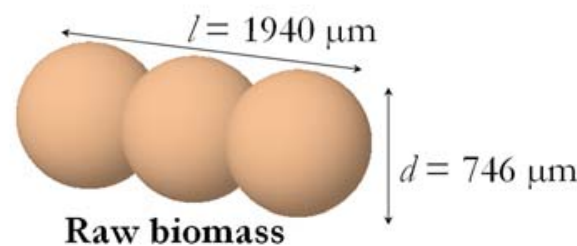

Raw biomass
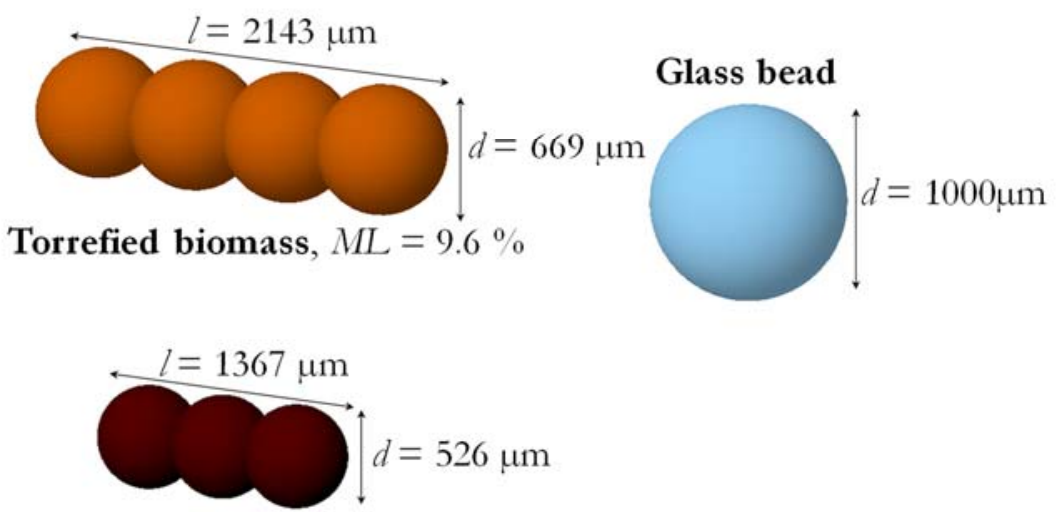

Torrefied biomass, $M L=24.5 \%$

Figure 3. Multisphere particle representation. (a). Nomenclature of main dimensions within a multisphere clump. (b). Models of biomass samples and glass bead used in DEM simulations (non-scaled, true relative size).

\subsection{Particle size upscaling and material model calibration}

Using simplified shape representations of the actual particle shape is a common practice. However a realistic material behavior has to be ensured through calibration [81].

The material DEM model of biomass powders was calibrated using the procedure described in detail in $[59,82]$. Calibration of the inter-particle coefficients of sliding $\left(\mu_{s}\right)$ and rolling friction $\left(\mu_{r}\right)$ and the Cohesion energy density $(C E D)$ was performed by comparing experimental bulk measurements against results of DEM simulations. The tested values for $\mu_{s}$ and $\mu_{r}$ varied between 0.1 and 0.9 and between 0 and $80 \mathrm{~kJ} / \mathrm{m}^{3}$ for the $C E D$ parameter. The bulk responses used were: angle-of-repose from a heap, bulk density and a shear box retainment ratio. The minimization of the discrepancy between numerical and experimental results was carried out using a Non-Dominate Sorting Genetic Algorithm (NSGA-II) [83], proven successful in previous research for DEM calibration [82]. Two objective functions were defined: $O_{1}$, the relative error between the simulated angle-of-repose and bulk density and the experimental values, and $\mathrm{O}_{2}$, the relative error between the experimental and simulated shear ratio. The shear ratio corresponded to the ratio of the number of particles remaining inside a shear box after the outlet lid was lifted and the initial number of particles poured into the box.

According to the dimensions of the particle clumps reported in Table 3, to simulate the formation of a full heap, several hundreds of thousands of particles would have to be included in the simulation domain, which would require several weeks of computation. Consequently, a coarse-graining approach $[54,55,57]$ was followed and a trade-off between the actual representation accuracy and the calculation effort was made by scaling particle size up by a factor of 4 . This led to a computation time for a typical heap formation simulation of ca. 1 hour and ca. 1 week for the simulation of three drum rotations.

Following the procedure described in [59] led to a population of optimal possible combinations of parameters that adjusted well the physical responses obtained from bulk setups. Preliminary simulations showed that low values of $C E D$ (e.g. $10 \mathrm{~kJ} / \mathrm{m}^{3}$ ) did not yield a qualitative cohesive behavior in the rotating 
drum simulations (revealed in the experiment by an irregular powder surface or the generation of particle agglomerates) for the raw biomass sample. Similar observations have been made by Nasato et al. [55] where too low cohesive forces in simulations of a shear test led to an identical flow behavior of a non-cohesive Hertz contact model. Therefore, the values of $\mu_{s}, \mu_{r}$ and $C E D$ used for rotating drum simulations (Table 4) were selected among the optimal parameter sets with the highest values of CED [59]. Values for glass beads reported in Table 4 were taken from [84]. Except for CED, particle-walls interaction parameters were set based on literature values for woody materials $[81,85]$. In line with previous research $[86,87]$, particle-steel $C E D$ was set at half the value of the interparticle $C E D$.

Table 4. DEM simulation parameters for particles and walls.

\begin{tabular}{|c|c|c|c|c|}
\hline Parameter & $\begin{array}{l}\text { Glass } \\
\text { beads }\end{array}$ & $\begin{array}{l}\text { Raw } \\
\text { biomass }\end{array}$ & $\begin{array}{c}\text { Torrefied } \\
M L=9.6 \%\end{array}$ & $\begin{array}{c}\text { Torrefied } \\
M L=24.5 \%\end{array}$ \\
\hline Poisson's ratio (particle-particle) & 0.22 & 0.3 & 0.3 & 0.3 \\
\hline Poisson's ratio (particle-walls) & 0.22 & 0.3 & 0.3 & 0.3 \\
\hline Particle density, $\mathrm{kg} / \mathrm{m}^{3}$ & 2550 & 350 & 350 & 350 \\
\hline Young's modulus (particle-particle), $\mathrm{Pa}$ & $5 \times 10^{6}$ & $5 \times 10^{6}$ & $5 \times 10^{6}$ & $5 \times 10^{6}$ \\
\hline Young's modulus (particle-walls), $\mathrm{Pa}$ & $5 \times 10^{6}$ & $5 \times 10^{6}$ & $5 \times 10^{6}$ & $5 \times 10^{6}$ \\
\hline $\begin{array}{l}\text { Coefficient of restitution (particle- } \\
\text { particle) }\end{array}$ & 0.87 & 0.1 & 0.1 & 0.1 \\
\hline $\begin{array}{l}\text { Coefficient of restitution (particle- } \\
\text { walls) }\end{array}$ & 0.87 & 0.1 & 0.1 & 0.1 \\
\hline $\begin{array}{l}\text { Sliding friction coefficient (particle- } \\
\text { particle) }\end{array}$ & 0.2 & 0.1 & 0.3 & 0.693 \\
\hline $\begin{array}{l}\text { Sliding friction coefficient (particle- } \\
\text { steel) }\end{array}$ & 0.6 & 0.4 & 0.4 & 0.4 \\
\hline $\begin{array}{l}\text { Sliding friction coefficient (particle- } \\
\text { glass) }\end{array}$ & 0.2 & 0.5 & 0.5 & 0.5 \\
\hline $\begin{array}{l}\text { Rolling friction coefficient (particle- } \\
\text { particle) }\end{array}$ & ---- & 0.7 & 0.3 & 0.131 \\
\hline $\begin{array}{l}\text { Rolling friction coefficient (particle- } \\
\text { walls) }\end{array}$ & ---- & 0.5 & 0.5 & 0.5 \\
\hline $\begin{array}{l}\text { Cohesion Energy Density (particle- } \\
\text { particle), } \mathrm{J} / \mathrm{m}^{3}\end{array}$ & ---- & 50049 & 77576 & 79062 \\
\hline $\begin{array}{l}\text { Cohesion Energy Density (particle- } \\
\text { steel) }, \mathrm{J} / \mathrm{m}^{3}\end{array}$ & ---- & 25024 & 38788 & 39531 \\
\hline Time-step (s) & $1.5 \times 10^{-5}$ & $1 \times 10^{-5}$ & $1.5 \times 10^{-5}$ & $1 \times 10^{-5}$ \\
\hline Total number of spheres & 19791 & 39366 & 34288 & 72816 \\
\hline Number of clumps & ---- & 13122 & 8572 & 24272 \\
\hline Number of processors & 8 & 2 & 4 & 8 \\
\hline
\end{tabular}




\subsection{Simulated system description}

The upscaled calibrated particle models were first used in simulations of the rotating drum at its actual dimensions. However, due to the upscaled particle size, very few grains were included in the domain when the real cylinder dimensions were used in simulations. This, combined with the resulting very high wall effects, prompted us to scale the cylinder dimensions up by a factor of 4 (i.e. to use an 'exact scaling' approach $[41,53,88])$. Although the use of an exact scaling approach offers no advantage regarding the simulation time, it provides a sufficient number of particles in the simulation domain to reproduce a macroscopic bulk behaviour of the material. Considering the large number of particles to be simulated, the application of a periodic boundary conditions ( $\mathrm{PBC}$ ) approach was explored on a preliminary basis.

Indeed, besides particle size scaling, another approach commonly used to increase computational efficiency in symmetric axial geometries such as cylinders, is to apply periodic boundary conditions in the axial direction [89]. This approach considers the bed of particles as an infinite array of identical translated layers of itself. Particles exiting one end of an axial boundary re-enter at the opposite boundary. Therefore, the effects of the endplates are not considered and only a thinner slice representing the center of the drum needs to be simulated, which could drastically reduce the computing time compared to the full system.

A cylindrical slice of the drum of $20 \mathrm{~mm}$ wide and $400 \mathrm{~mm}$ in diameter was used for PBC simulations. This width (axial dimension) of the disc corresponded to $1 / 4$ of the scaled width. Figure 4 shows a comparison between experimental images for a biomass sample and glass beads (Figure $4 \mathrm{a}$ and d), snapshots of the corresponding simulations using PBC (Figure $4 \mathrm{~b}$ and e) and images using a closed geometry with the same width and endplates (Figure 4c and f). The behavior obtained from DEM simulations with PBC did not correspond to the experimental observations: in the case of the glass bead samples, a slumping rather than a continuous regime developed [16], while for biomass samples, the powder collapsed on itself at very low $\alpha$ angles. Simulations using glass endplates reproduced better the experimental behavior displaying correct qualitative features: a continuous flow regime with a constant slope developed for glass beads and high-potential avalanches took place for biomass. This shows that the inclusion of wall friction effects is required to simulate a realistic flow. Therefore, the final simulated drum configuration included these endplates.

The main drum dimensions used for simulations are presented in Table 5. It should be noted that to reduce computing time, the cylinder width used for PBC simulations was kept in the finally simulated system. The number of particles between endplates for the elongated biomass samples $(n)$ is calculated based on the equivalent diameter of the clumps $n=w /\left(d_{e q} \times 4\right)$ (Table 3). The values of $n$ were in all cases above 4 . Johnstone [43] reported that four particles between the endplates were a good compromise between computational time requirement and the accuracy of the dynamic angle determination. For each sample, the number of particles to achieve a $40 \%$ fill volume is also reported in Table 5 . The values for biomass samples correspond to the number of elongated clumps, so the total number of simulated individual spheres correspond to the value reported in Table 5 multiplied by the number of spheres per clump.

As in experiments, the rotational speed of the drum was $0.5 \mathrm{rpm}$. The randomly-oriented particles were inserted into the cylinder volume and allowed to settle for 10000 timesteps. Previous research by Marigo [52] on cohesionless alumina cylindrical pellets has shown that a steady-state could be achieved after one rotation while DEM simulations of plastic balls by Liu et al. [90] needed at least two rotations to reach steady state. Mishra et al. [46] reported the attainment of a steady-state for agglomeration of cohesive particles inside a rotating drum after 1.5 revolutions of the drum. In this work, simulations were conducted for a duration equivalent to 3 drum rotations (360 s). 
Table 5. Characteristics of the simulated rotating drum system.

\begin{tabular}{llr}
\hline \multirow{2}{*}{ Drum diameter } & Glass beads & $100 \mathrm{~mm}$ \\
& Biomass samples & $400 \mathrm{~mm}$ \\
\hline \multirow{2}{*}{ Drum width $(w)$} & Glass beads & $5 \mathrm{~mm}$ \\
& Biomass samples & $20 \mathrm{~mm}$ \\
\hline \multirow{3}{*}{ Number of particles between endplates $\left(w / d_{e q}\right)$} & Glass beads & 5 \\
& Raw biomass & 4.7 \\
& Torrefied, $M L=9.6 \%$ & 4.8 \\
& Torrefied, $M L=24.5 \%$ & 6.7 \\
\hline \multirow{3}{*}{ Number of elongated clumps in domain } & Glass beads & 19791 \\
& Raw biomass & 19376 \\
& Torrefied, $M L=9.6 \%$ & 8572 \\
& Torrefied, $M L=24.5 \%$ & 24272 \\
\hline
\end{tabular}

Torrefied biomass, $M L=24.5 \%$

(a)

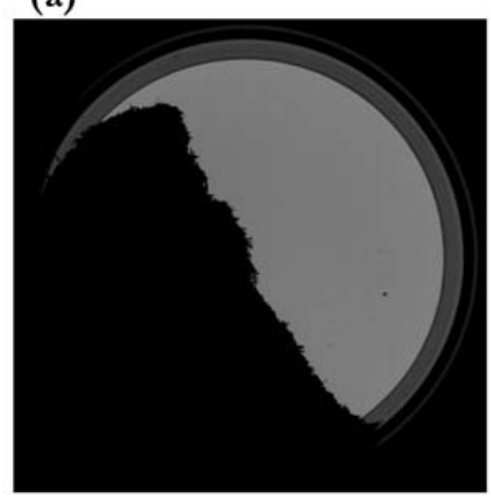

Glass beads

(d)

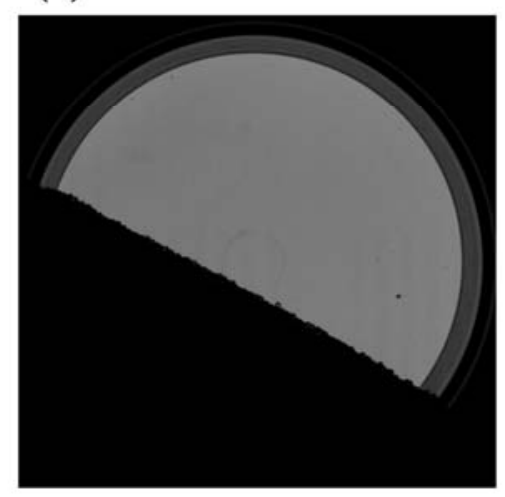

(b)

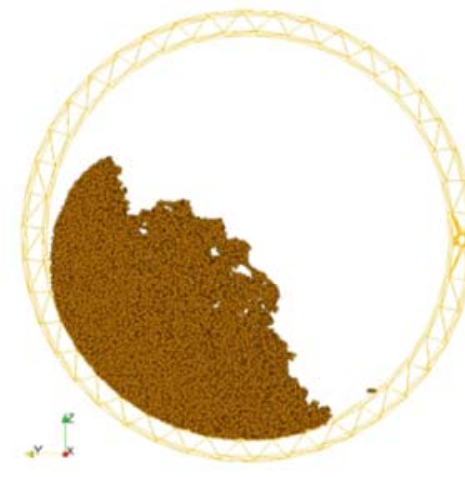

(e)

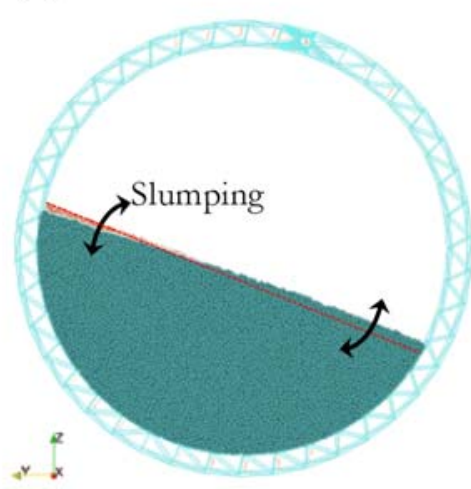

(c)

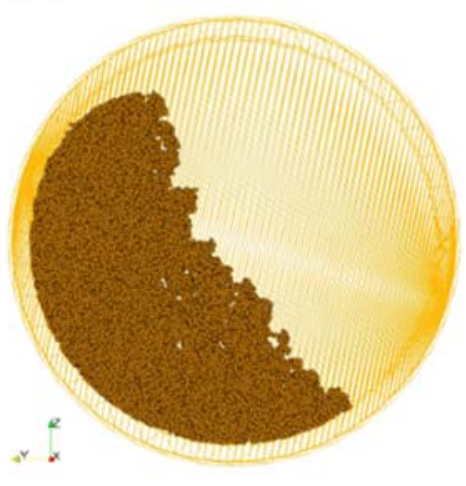

(f)

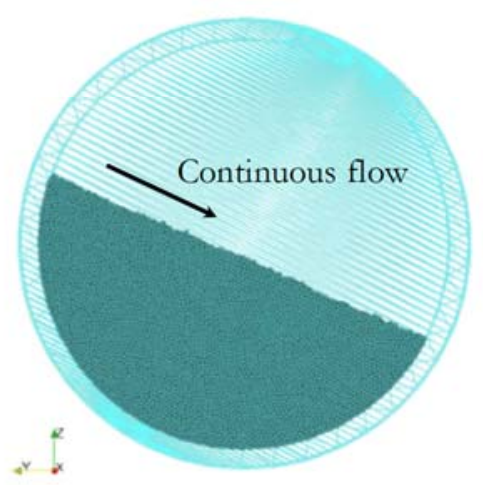

Figure 4. Experimental and DEM-simulated motion inside the rotating drum for torrefied biomass and glass beads samples. (a,d). Experimental images. (b,e). DEM simulation snapshots using PBC. $(c, f)$. DEM simulations with endplates. 


\section{RESULTS AND DISCUSSION}

In this section, comparisons between the experimental behavior and DEM simulations are made, firstly, based on the visual observations of the material motion and then from quantitative flowability indicators. The experimental results presented here have been thoroughly discussed in [66] so that the analysis hereafter focuses on the description of the numerical results and their comparison with the observed experimental behavior.

Figure 5 shows a qualitative comparison between representative experimental and simulation captions after avalanches. Visually, the similarities between the simulation and the experimental results are encouraging. Overall, the differences in behavior between the different samples studied here are well captured by the DEM simulations.

(a) Glass beads
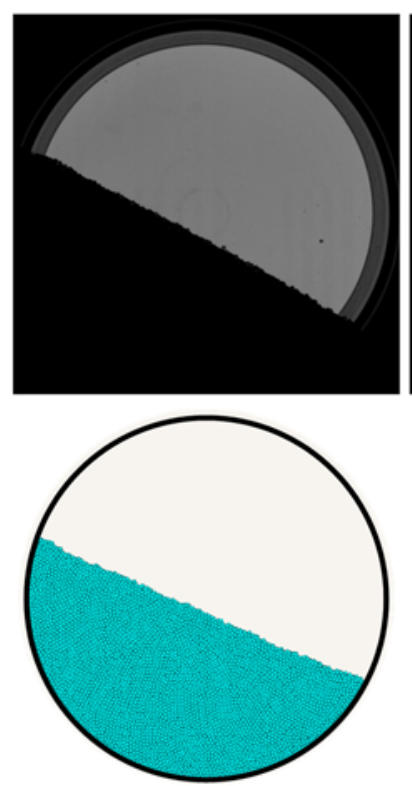

(b) Raw biomass
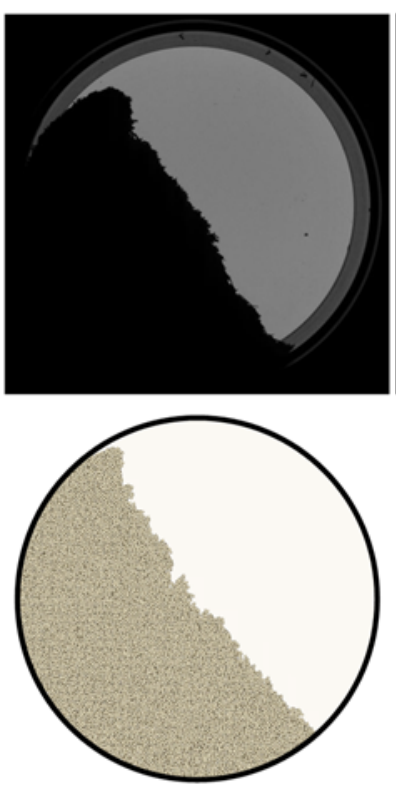

(c) $M L=9.6 \%$
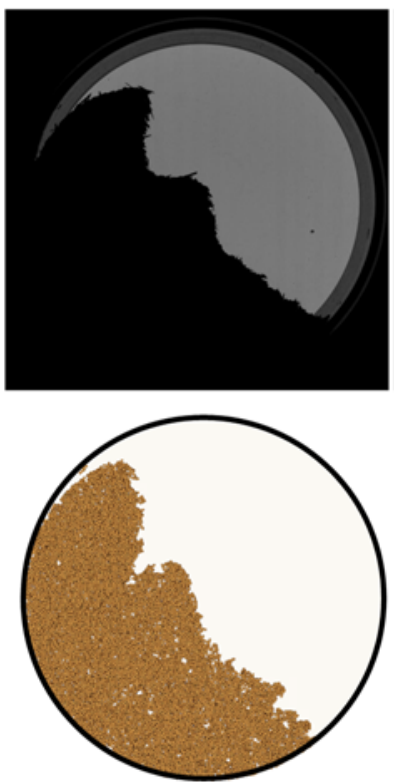

(d) $M L=24.5 \%$
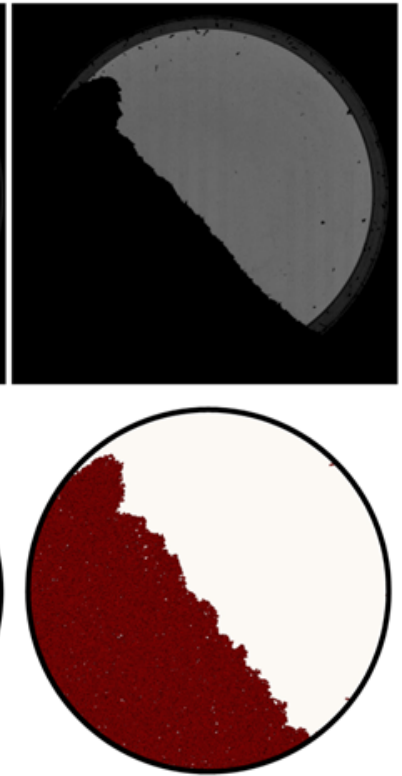

Figure 5. Typical experimental and simulated post-avalanche profiles after one rotation.

Both experimentally and numerically, a continuous regime of flow develops for glass beads with little variations of the flat free-surface slope. For biomass samples, qualitatively, the motion of the powder bed occurs in the form of intermittent collapses of particle clusters, which is a characteristic behavior of cohesive materials [21]. This led to irregular free-surface profiles after avalanches that are well reproduced by simulations. This behavior is more pronounced for the mildly torrefied sample (Figure 5c), for which very rugged and irregular profiles are observed. In all cases, simulations led to a higher roughness of the freesurface than that observed in experiments. A higher apparent porosity of the powder bed compared to experiments is also visible in the simulations, which is likely to be mainly a visualization effect, since the width of the simulated drum (i.e. the number of axially superposed particles) was reduced compared to the real setup.

The temporal evolution of the centroid angle $\alpha$ during one drum rotation is shown Figure 6 . Numerically, for glass beads, it took $8 \%$ of rotation to trigger the first avalanche, while for biomass powders around $20 \%$ of a rotation was needed. After the first avalanche, both numerically and experimentally, there is no clear evolution towards a steady-state in terms of the centroid angle, so the segments showed in Figure 6 can be considered as qualitatively representative of the entire simulated period ( 3 drum rotations). 
The qualitative behavior of the four samples in terms of $\alpha$ evolution was well reproduced by simulations. Both numerically and experimentally, for glass beads, there are very rapid and very short variations of $\alpha$ of up to $2^{\circ}$ while, for biomass, there is a succession of large quasiperiodic events consisting in decreases of $\alpha$ of up to $20^{\circ}$. Small random events are also common for the simulations of both raw and mildly torrefied biomass (Figure $6 \mathrm{~b}$ and $\mathrm{c}$ ) while a more regular pattern of large events (nearly uniform in size and time spacing) is visible for the intensively torrefied sample (Figure 6c). Quantitatively, it is however apparent from Figure 6 that there is an evident minor quantitative gap between experimental results and simulations.

The flowability parameters explained in Section 2.2 were evaluated from the experimental and simulation results and used to quantitatively differentiate the cohesiveness of the different powders.

(a) Glass beads

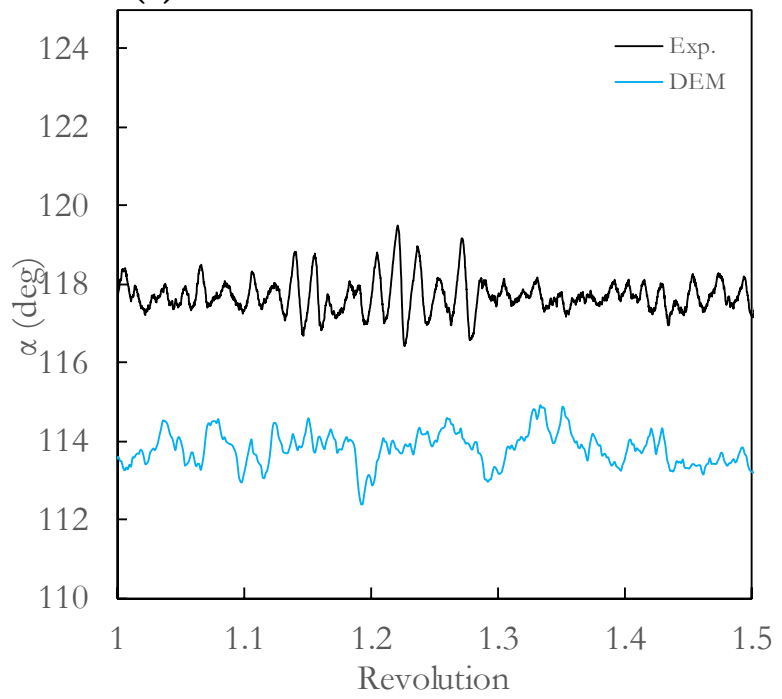

(c) Torrefied, $M L=9.6 \%$

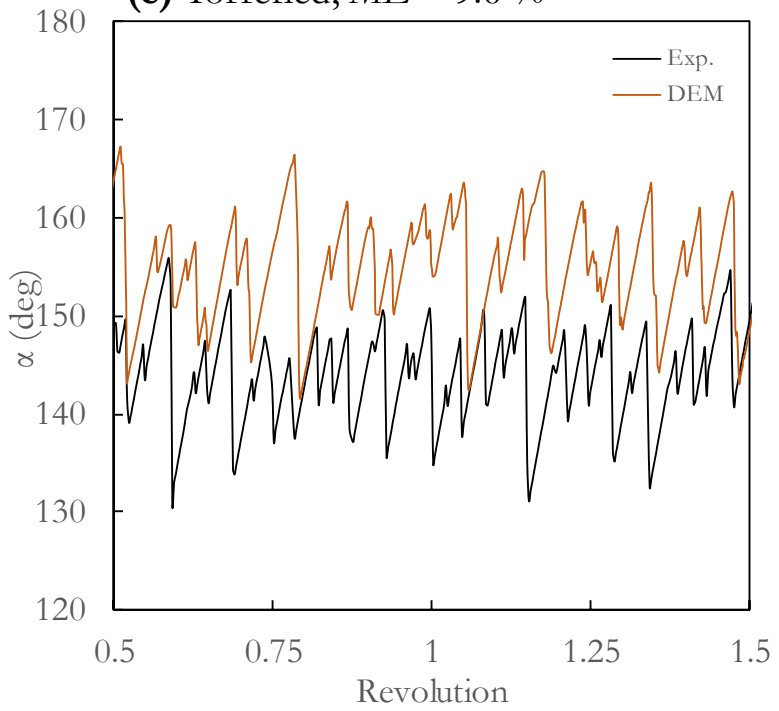

(b) Raw biomass

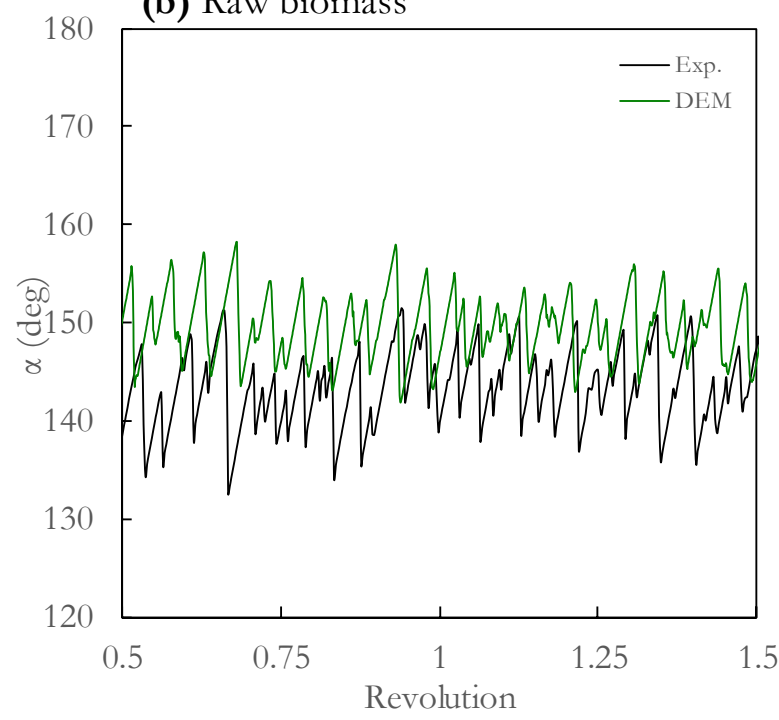

(d) Torrefied, $M L=24.5 \%$

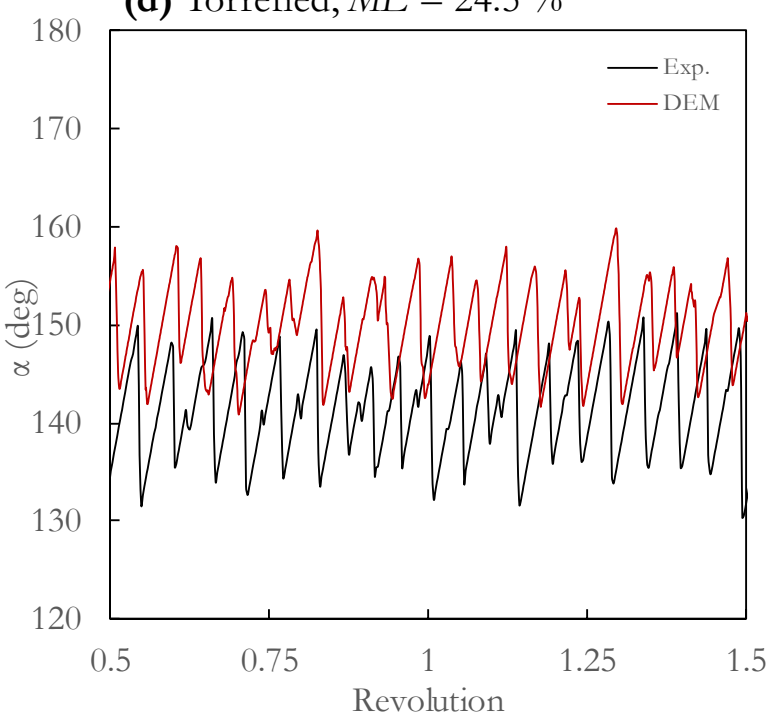

Figure 6. Experimental and DEM-modelled evolution of the 'centroid angle'. The $x$-axis ('Revolution') is the fraction of rotation (i.e. the product between the rotational speed and the elapsed time in homogeneous units).

Because of the highly variable profiles shown in Figure 6, the flowability parameters are presented in Figure 8 in terms of occurrence distributions rather than simply as average values. The median values of the distributions $\left(50^{\text {th }}\right.$ centile) are reported in Table 6 and used to establish flowability rankings. Quantitatively, 
the width of the distributions for a given flowability parameter ' $\varepsilon$ ' is quantified by the span $S_{\varepsilon}$, calculated as follows:

$$
S_{\varepsilon}=\frac{\varepsilon_{90}-\varepsilon_{10}}{\varepsilon_{90}+\varepsilon_{10}}
$$

where $\varepsilon_{90}$ and $\varepsilon_{10}$ are the $90^{\text {th }}$ and $10^{\text {th }}$ centiles of the cumulative $\varepsilon$-distributions, respectively.

Figure 7 shows the cumulative distributions for the upper angle of stability obtained from the experimental results (Figure 7a) and the DEM simulations (Figure 7b). Overall, the behavior for simulations and experiments in terms of $U A S$ is similar: a very steep unimodal distribution is obtained for the glass beads, around a value a few tens of degrees lower than that of biomass powders, which is indicator of a free-flowing behavior. In the case of the biomass powders, the distributions spread over a wider range of values, as can be expected from the plots in Figure 6 . The raw and the intensively torrefied samples exhibit very close $U A S$ distributions, while the mildly torrefied samples have greater $U A S$ values, indicating a higher cohesive nature.

In addition to interparticle interactions, the moment at which particles detach from the drum walls is likely to be strongly influenced by the wall-particle particle-wall interactions, namely the coefficients of friction and the cohesion energy. These parameters were not considered in the calibration framework (Section 3.3). This might explain the quantitative offset of the DEM distributions compared to the experimental results. Nevertheless, results of Table 6 for $U A S$ show that DEM simulations predicted within a low margin of error (below $7 \%$ ) the experimental values. 
(a) EXPERIMENTS

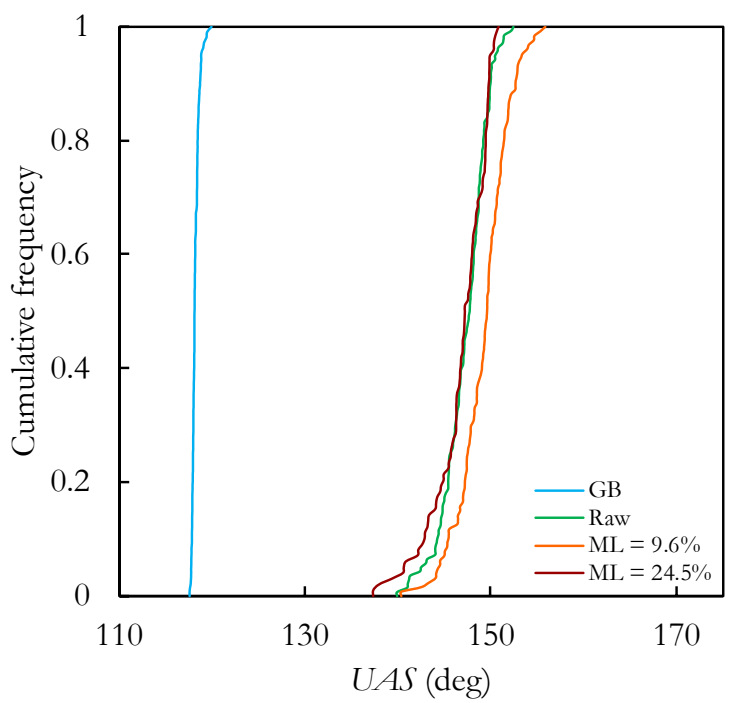

(c)

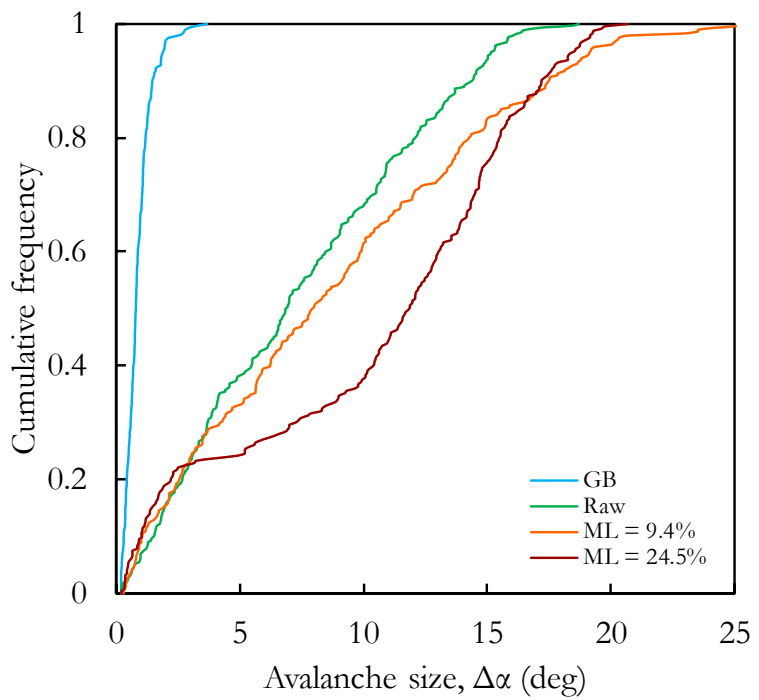

(e)

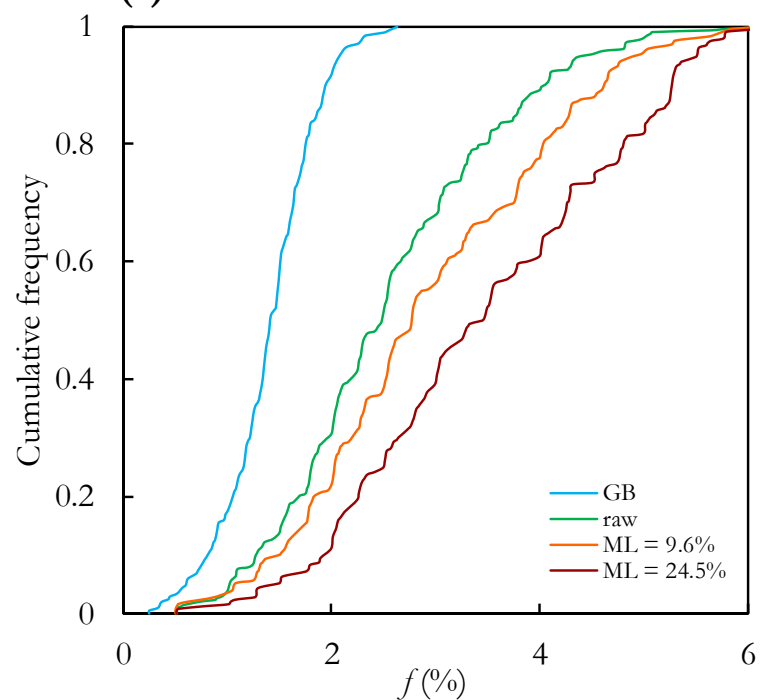

(b)

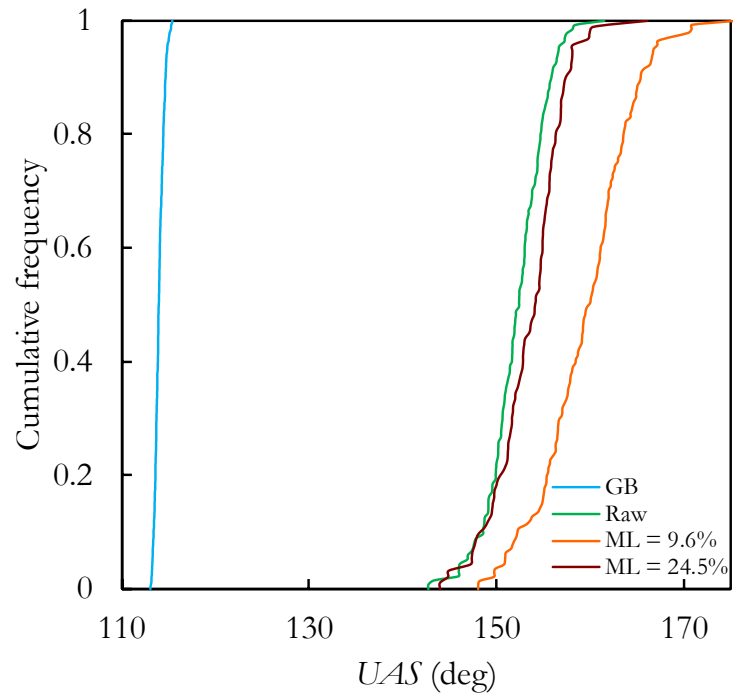

(d)

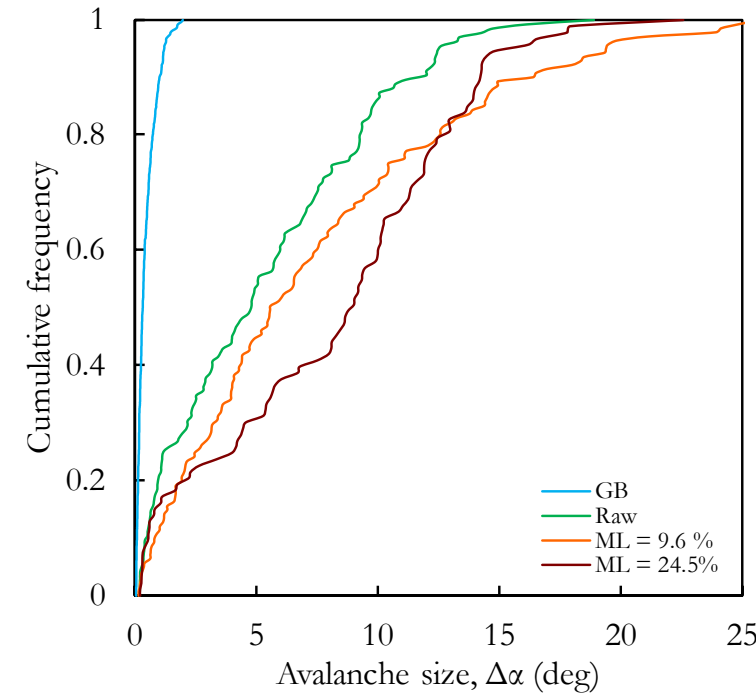

(f)

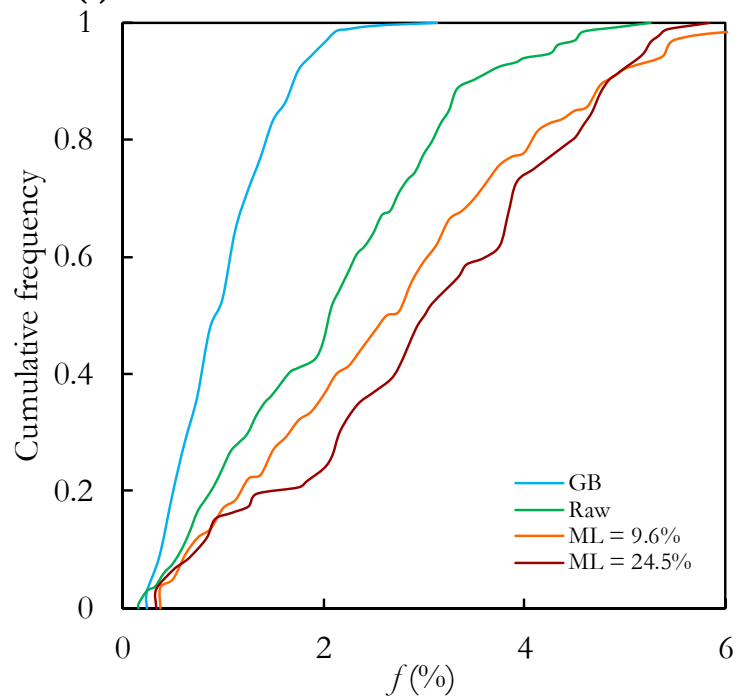

Figure 7. Distributions of flowability descriptors. Left-side plots correspond to the experimental results, right-side are the results obtained from DEM simulations. (a,b) UAS. (c,d) Avalanche size. (e,f) Fraction of revolution needed to trigger events. 
Figure $7 \mathrm{c}-\mathrm{d}$ compares the experimental and simulated avalanche size $(\Delta \alpha)$ distributions. While very short avalanches were observed for glass beads, which is characteristic of a non-cohesive material, large angle variations during events were observed for the biomass powders. These large variations of $\alpha$ are produced by the tumbling of clusters of particles, measured experimentally and nicely reproduced numerically, which rapidly modify the center of mass of the powder bed. While the qualitative similarity between the plots in Figure 7 is encouraging, the average avalanche size (Table 6) was always underestimated by the DEM simulations. However, the same experimental and numerical ranking of flowability could be established.

Table 6. Experimental and simulated results for several flowability indicators. Span values (Eq. 10) are indicated in round brackets, flowability ranking is reported in square brackets from I being the worst flowing material to IV the material with the best flowability. The relative error is referred to as $\mathrm{e}$.

\begin{tabular}{|c|c|c|c|c|c|c|c|c|c|c|c|c|}
\hline & \multicolumn{3}{|c|}{$U A S_{50}\left(S_{U A S}\right)(\mathrm{deg})$} & \multicolumn{3}{|c|}{ Avalanche size $\Delta \alpha(\mathrm{deg})$} & \multicolumn{3}{|c|}{$f_{50}\left(S_{f}\right)(\%)$} & \multicolumn{3}{|c|}{$r_{50}^{2}\left(S_{r^{2}}{ }^{2}\right)$} \\
\hline Sample & Exp. & DEM & $\begin{array}{c}\mathrm{e} \\
(\%)\end{array}$ & Exp. & DEM & $\begin{array}{c}\mathrm{e} \\
(\%)\end{array}$ & Exp. & DEM & $\begin{array}{c}\mathrm{e} \\
(\%)\end{array}$ & Exp. & DEM & $\begin{array}{c}\mathrm{e} \\
(\%)\end{array}$ \\
\hline \multirow{3}{*}{ Glass beads } & 118.1 & 114.0 & & 0.81 & 0.32 & & 1.41 & 0.93 & & 0.999 & 1.00 & \\
\hline & $(0.004)$ & $(0.006)$ & 3.5 & (0.64) & (0.85) & 60.5 & $(0.42)$ & $(0.63)$ & 34.0 & $(0.00)$ & $(0.00)$ & 0.1 \\
\hline & {$[\mathrm{IV}]$} & [IV] & & [IV] & [IV] & & [IV] & [IV] & & [IV] & [IV] & \\
\hline \multirow{3}{*}{ Raw biomass } & 147.7 & 152.4 & & 6.84 & 4.79 & & 2.48 & 2.06 & & 0.966 & 0.98 & \\
\hline & $(0.02)$ & (0.024) & 3.2 & $(0.80)$ & $(0.92)$ & 30.0 & $(0.52)$ & $(0.71)$ & 16.9 & (0.030) & $(0.02)$ & 1.5 \\
\hline & [II] & [III] & & [III] & [III] & & [III] & [III] & & [II] & [III] & \\
\hline \multirow{3}{*}{$\begin{array}{l}\text { Torrefied, } \\
M L=9.6 \%\end{array}$} & 149.6 & 159.8 & & 7.98 & 5.61 & & 2.77 & 2.62 & & 0.956 & 0.68 & \\
\hline & $(0.02)$ & $(0.041)$ & 6.8 & $(0.88)$ & $(0.90)$ & 29.7 & $(0.51)$ & $(0.76)$ & 5.5 & $(0.040)$ & $(0.36)$ & 28.9 \\
\hline & [I] & [I] & & [II] & [II] & & [II] & [II] & & [I] & [I] & \\
\hline \multirow{3}{*}{$\begin{array}{l}\text { Torrefied } \\
M L=24.5 \%\end{array}$} & 147.2 & 154.1 & & 11.8 & 8.88 & & 3.44 & 3.00 & & 0.991 & 0.96 & \\
\hline & $(0.02)$ & $(0.03)$ & 4.7 & $(0.89)$ & $(0.93)$ & 24.7 & $(0.46)$ & $(0.74)$ & 12.8 & $(0.014)$ & $(0.11)$ & 3.13 \\
\hline & {$[\mathrm{III}]$} & {$[\mathrm{II}]$} & & [I] & [I] & & [I] & [I] & & [III] & [II] & \\
\hline
\end{tabular}

Similar observations can be made from Figure 7e-f regarding the fraction of revolution $f$ needed to trigger events. Again, lower fractions were obtained for glass beads, indicating a greater ease of flow. For the biomass samples, events required a larger fraction of revolution to occur, i.e. they were triggered less frequently, which is an indicator of a reduced flowability. Qualitatively, the shape and locations of the simulated $f$-distributions were consistent with the experimental results. Lower discrepancies between the average simulated and the experimental values of $f$ were obtained for the biomass materials than for the glass beads (Table 6), and the same flowability ranking as in the experiments could be established. Intensively torrefied samples were less prone to flow in terms of event frequency, followed by the mildly torrefied sample, the raw sample and finally the non-cohesive glass beads. A comprehensive critical analysis on the use of the $f$ parameter as indicator of flowability has been made in previous research [91]. The identification of the type of events is also important to conclude on flowability when using this indicator. For the intensively torrefied samples, even if the events are more spaced over time, the representations in Figure $6 \mathrm{~d}$ show that there are fewer 'small' events for these materials than for the mildly torrefied or the raw samples. These small events were associated to small clumps breakings over the powder bed, which are typical of a cohesive flow. Experimentally, the flow of the intensively torrefied samples was dominated by 'large' shearflow events rather than 'small' clumps breaks. This behavior was also verified by visual observation of the simulation output. This highlights the importance of considering the type of motion taking place during avalanches, and not only isolated numerical indicators of the event frequency or size.

The evaluation of the coefficient of determination $\left(r^{2}\right)$ completes the analysis of flowability by examining the irregularity of the free-surface profile of the powder. Figure 8a-b correspond to the evolution of $r^{2}$ obtained from experiments and simulations for the glass beads and the raw biomass sample. While for the glass beads the values of $r^{2}$ are nearly constant at ca. 1, for the biomass powder great deviations from a linear 
profile develop, especially during avalanches. The very distinct behavior between the non-cohesive and the cohesive materials was well reproduced by simulations as can be seen in Figure 8: a high irregularity was observed for the biomass sample compared to the glass beads.

(a)

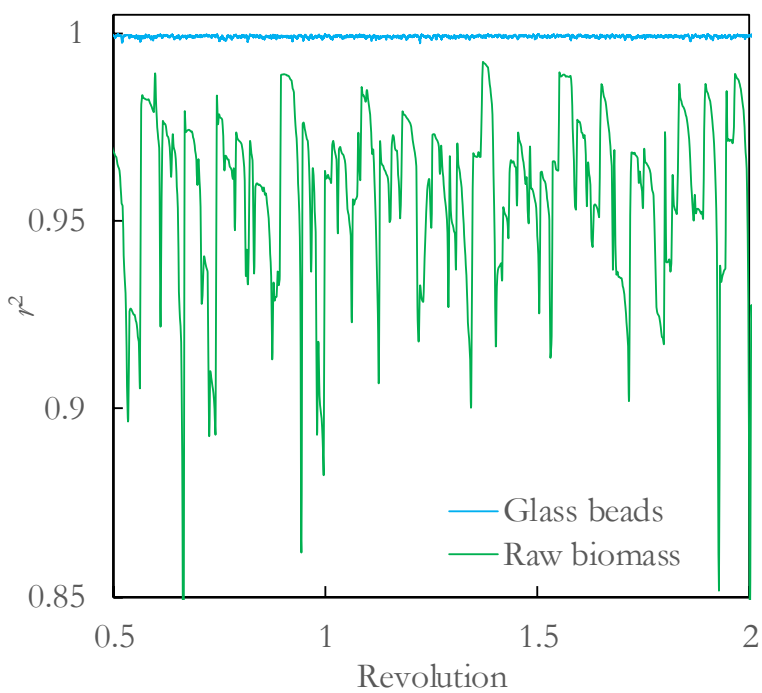

(c)

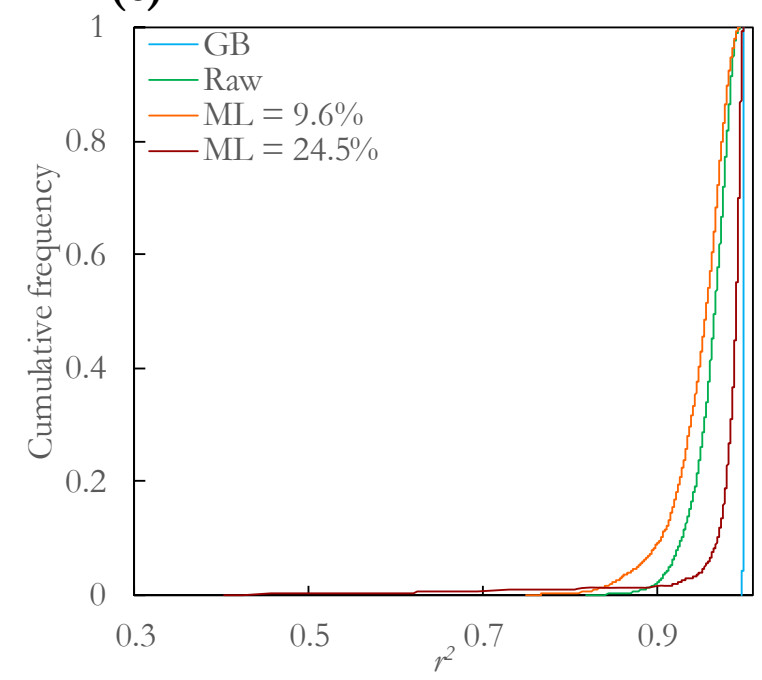

DEM SIMULATIONS

\section{(b)}

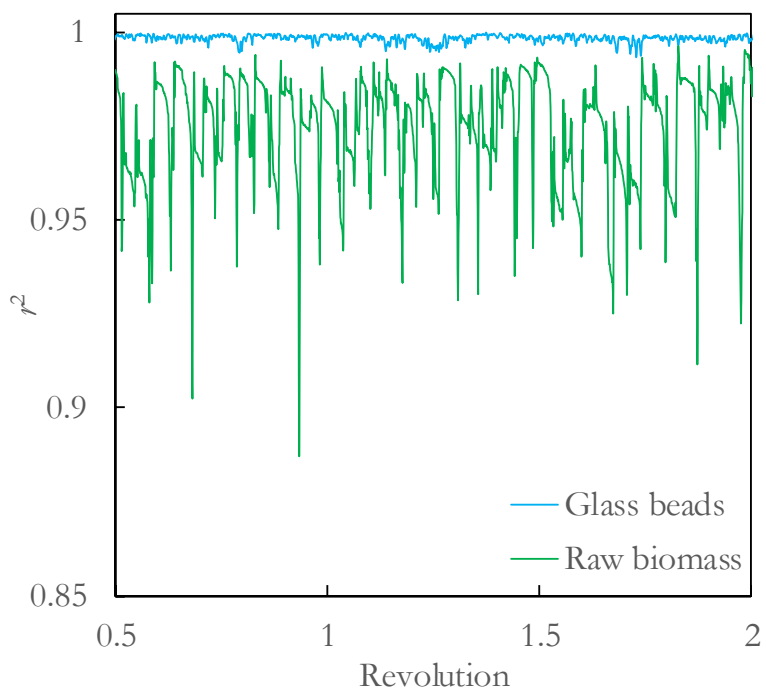

(d)

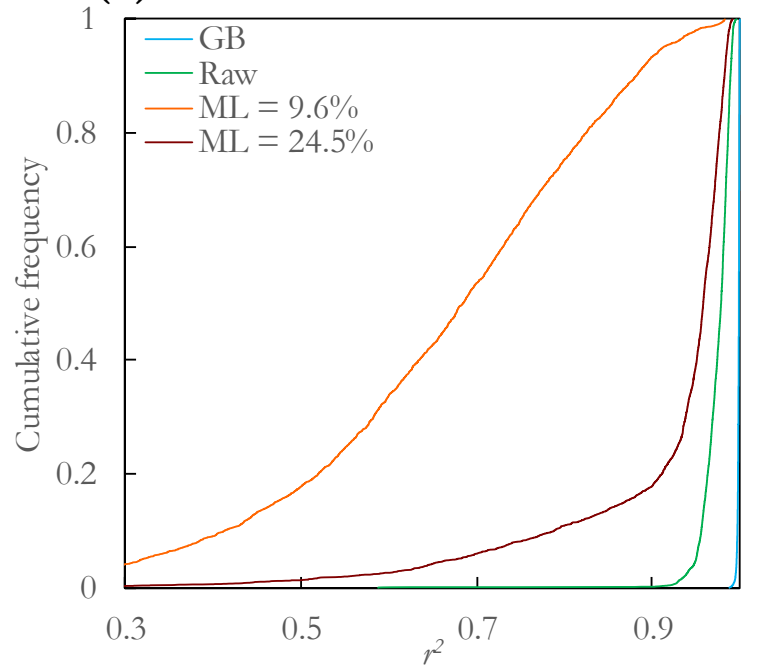

Figure 8. Irregularity of the free-surface profile as measured by the coefficient of determination $\left(r^{2}\right)$. (a) Experimental evolution for raw biomass and glass beads. (b) Simulated evolution for raw biomass and glass beads. (c) Experimental $r^{2}$-distributions. (d) $r^{2}$-distributions from simulation results

The cumulative distributions in Figure 8c-d were derived from the evolution of $r^{2}$ over time. The comparison of experimental and simulated distributions reveals rather significant differences. The coarse grained model of particles led to powder beds with a free surface profiles that were 'rougher' than in experiments. An overestimation of the cohesive strength (i.e. the CED values in the DEM models) could also trigger more irregular profiles as a more cohesive behavior develops compared to the experimental behavior. This can be seen in Figure 6 where the evolution of the centroid for the biomass powders is always higher than the experimental trends. A finer calibration of the CED value, that appears to have a significant impact on the flow patterns may be recommended.

Most striking are the significantly low values of $r^{2}$ obtained for the mildly torrefied samples from simulations. This is the combined result of the high CED value for this sample and its higher elongation 
that led to very rough and irregular profiles. Except for for mildly torrefied samples, the average values of $r^{2}$ were similar in simulations and in experiments (Table 6) and were used to establish a flowability ranking, with the mildly torrefied sample exhibiting the most cohesive behavior and the glass beads being noncohesive.

For all criteria, differences in the behavior showed between simulations and experiments are also likely to be the effect of the reduced number of events considered to draw the distributions from simulations. Indeed, in the experiments, distributions are calculated on the basis of about 3 times the number of events recorded for simulations (e.g. 145 events for raw biomass). Although the study of the effect of the number of events on the distributions obtained from simulations remains a concern of ongoing work, longer simulations would likely reduce experimental-DEM gaps.

One avenue left unexplored in this work is the relative cohesive strength of interaction of particles with the drum walls, which may have a strong influence on the powder motion (in particular the moment when particles detach from the walls). Further investigation and experimentation might evaluate calibration of particle-wall interaction parameters and their effects on the bulk flow.

The results presented here suggest that calibrated DEM parameters obtained from relatively easy-toimplement bulk setups (angle-of-repose, bulk density and a retainment ratio) could be used to reproduce a realistic dynamic non-consolidated flow of biomass particles. One might consider directly applying a calibration framework such as the one presented in [59] using rotating drum simulations and experiments to better adjust powder dynamic behavior. However, as highlighted by Hu et al. [27] and as noted in this work, the long computation time that would be required for calibration using indicators from a rotating drum makes this strategy impractical at present. Instead, the results obtained from avalanche assessment in rotating drums could be dedicated to narrow the population of optimal sets of parameters obtained from bulk experiments, with fewer/shorter simulations required. This leads to a more realistic and robust DEM material model and to a better representation of flow behavior under a wide range of flow conditions.

\section{Potential of DEM simulations for exploration of shape and cohesion effects on flow}

The previous results proved that DEM simulations are capable of representing a realistic bulk flow of biomass particles under dynamic free-surface conditions. One of the greatest strengths of the simulation approach is that it allows the effect of the powder characteristics such as particle size, shape or interparticle cohesion on bulk flow to be studied independently. An overview of this potential is given hereinafter.

Figure 9 shows simulation snapshots that illustrate the effect of changes in particle properties (shape and cohesion) on the powder profile. Figure 9a corresponds to non-cohesive spherical particles with an equivalent diameter equal to that of the raw biomass scaled clumps $\left(d_{e q}=2.12 \mathrm{~mm}\right)$, all the other DEM parameters being the same than those used for raw biomass simulations. Figure $9 \mathrm{~b}$ shows the effect of adding a cohesive contribution of $C E D=50.049 \mathrm{~kJ} / \mathrm{m}^{3}$ (i.e. $C E D$ for raw biomass particles reported in Table 4.). In Figure $9 \mathrm{c}$ the elongated shape of the raw biomass clumps is used but interparticle cohesive forces are neglected and Figure 9d corresponds to the simulated raw biomass sample with the parameters of Table 4. 

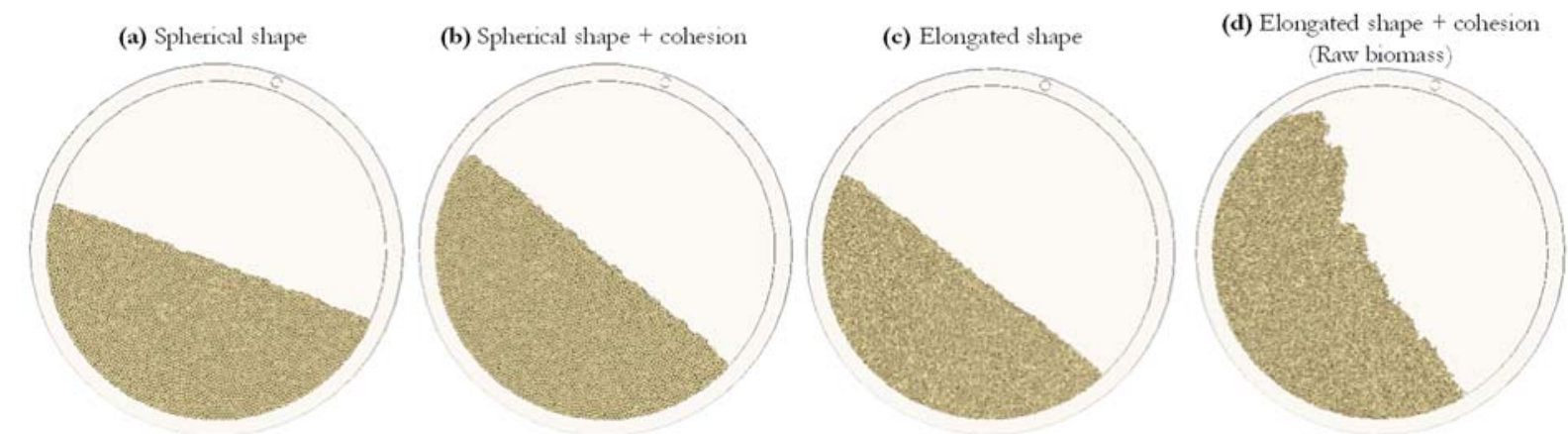

Figure 9. Snapshots of DEM simulations showing the effect of particle shape and interparticle cohesion on flow.

To facilitate the visualization of the dynamic flow behavior, snapshots of the flow with particles colored according to their instantaneous speed are presented in Figure 10 for two successive moments at $t_{i}$ and $t_{j}$. The ease of access to detailed information at the particle-scale highlighted by the representations in Figure 10 shows another interesting feature of DEM simulations. Figure 11 presents the evolution of the centroid angle during one rotation for the four cases presented in Figure 9 and Figure 10.

(a) Spherical shape

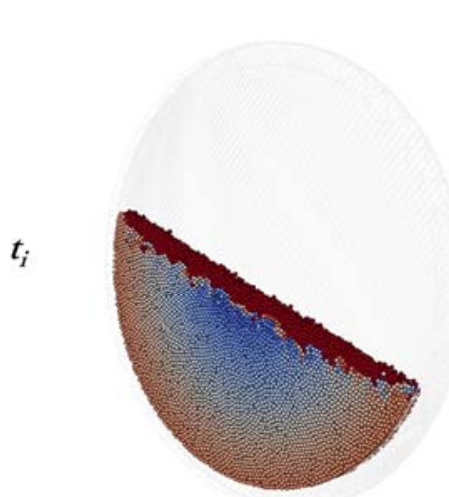

(b) Spherical shape + cohesion
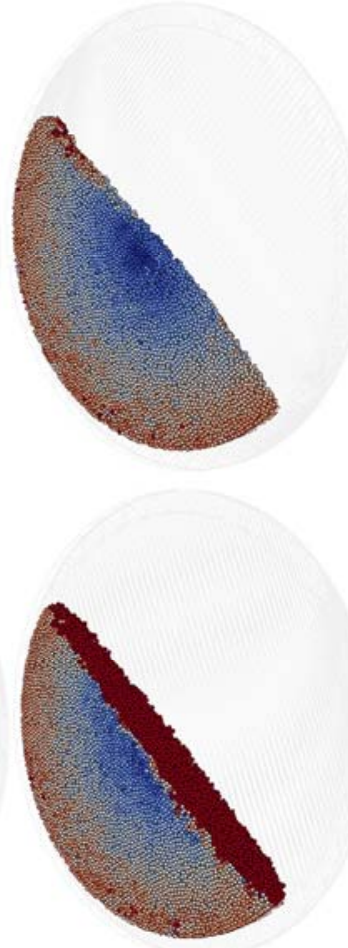

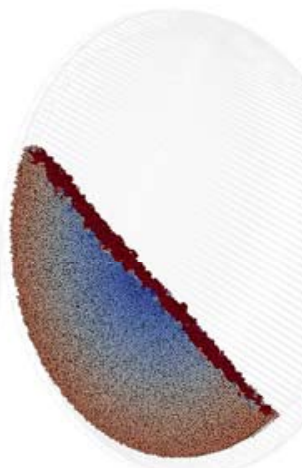

(c) Elongated shape

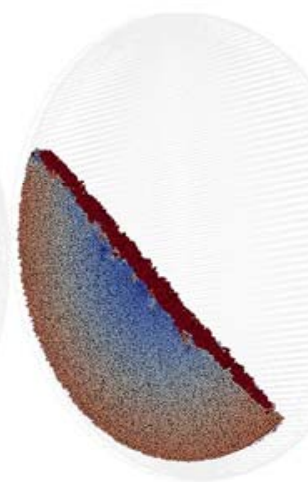

\section{$t_{j}$}

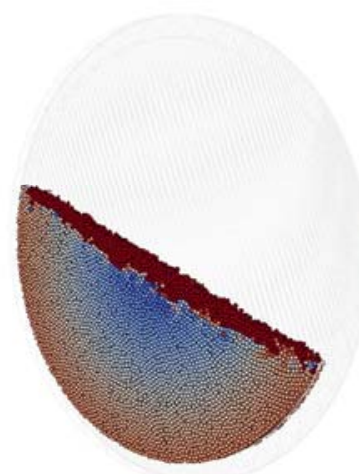

(d) Elongated shape

+ cohesion

(Raw biomass)

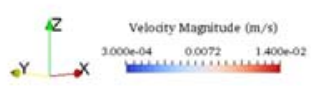

Figure 10. Effect of particle characteristics on the flow behavior at two different moments. The time interval between $t_{i}$ and ${ }_{i j}$ is generally the avalanche duration for the different material models, i.e. between 0.3 and 0.7 seconds. A similar time interval (c.a. 0.5 s) was used for the snapshots of models where a continuous regime developed (case a and $c$ ).

The lowest values of $\alpha$ were obtained for the non-cohesive spherical particles and, as for the glass beads, a continuous regime of flow developed with a flat and constant slope and a permanent layer of spheres 
rolling down the free-surface (Figure 10a). Adding a cohesive contribution not only increased the centroid angle (Figure 9b), but also resulted in a slumping regime in which periodic events took place: the solid bed was lifted (Figure 10b, top) and leveled off (Figure 10b, bottom) by successive small discrete avalanches at the surface.

Elongated shape promotes particle interlocking while limiting their free movement, which results in greater centroid angles than for spherical particles (Figure 9c). Equivalent results for the dynamic angle of repose are reported in previous research by Höhner et al. [39] and Wachs et al. [42]. Interestingly, without cohesive interactions, a continuous regime of flow develops as in the case of the spherical particles. Elongated particles simply shift the mean angle towards a higher value and the thickness of the shear front of particles continuously flowing over the powder bed decreases (Figure 10c). Figure 11 shows that the increase in the centroid angle triggered by the addition of cohesion (case b) or by an elongated shape (case c) is, in average, comparable (ca. $+20^{\circ}$ compared to the simulation of spherical particles). The difference between these two cases is the presence of short oscillations when a cohesive contribution is taken into account. Therefore, if only an average value of $\alpha$ had been considered for flowability characterization (as is often the case in literature), similar conclusions about flow would have been wrongly drawn for both cases. This underlines the importance of considering several flow indicators in addition to average angles.

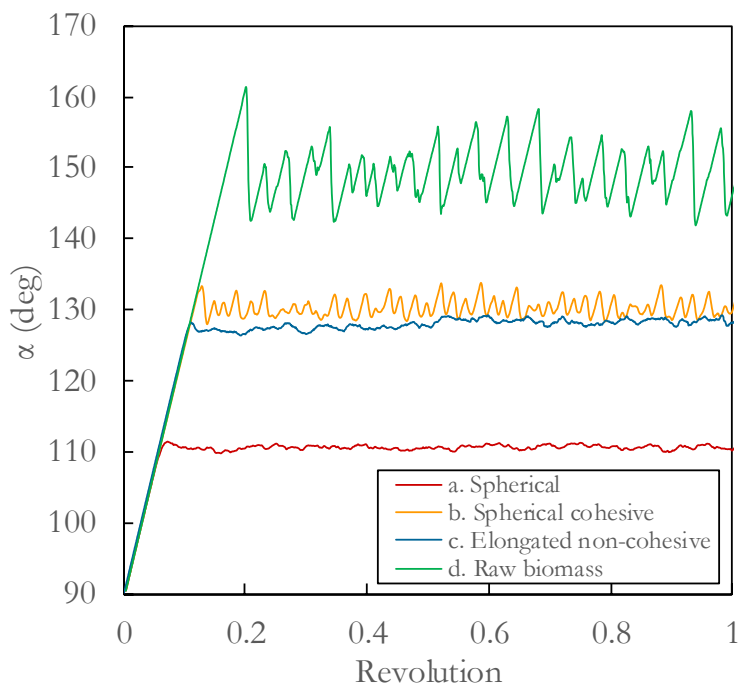

Figure 11. Effect of particle characteristics on the temporal evolution of a during one drum revolution.

As seen in Figure 9d, only the coupled effects of the elongated particle shape and the interparticle cohesion were able to reproduce a realistic behavior for the raw biomass samples, with discrete avalanches (Figure 10d top) and the formation of clusters of particles collapsing over the free-surface. This triggered the large $\alpha$ variations depicted in Figure 11 that closely mimic the experimental behavior.

In this study, only monodispersed populations of particles were used in the simulations. However, experimentally, although a sieving stage reduced the polydispersity of the biomass powders, there was still a variety of particle sizes, especially for the intensively torrefied samples, which is likely to influence flow behavior. A natural progression of this work is to analyze the effect of polydispersity on flow behavior through simulations. Although this will be the subject of future research, a first effort in this direction is shown here by simulating a polydispersed population with characteristics approximated from the PSD of the raw biomass sample. Thus, three particle sizes at $d_{8.2}(500 \mu \mathrm{m}), d_{50}(746 \mu \mathrm{m})$ and $d_{75}(890 \mu \mathrm{m})$ were combined with volume proportions of $25 \%, 50 \%$ and $25 \%$, respectively, maintaining the same average aspect ratio as the monodispersed system. As shown in Erreur! Source du renvoi introuvable., the inclusion of two additional particle sizes did not significantly change the bulk behavior in terms of the centroid angle evolution. Similar $U A S$ and $f$ distributions were thus obtained compared to those of the 
monodispersed raw biomass. However, the computing time was greatly increased due to the presence of finer particles which led to a higher number of particles to be simulated to reach the same fill ratio (19 376 for the polydispersed system compared to 13122 for the monodisperse raw biomass). This suggests that a polydisperse system could be adequately represented by a simplified monodisperse population, thus saving time in terms of calculation. Further work with a higher degree of polydispersity might be required to reinforce these findings.

(a)

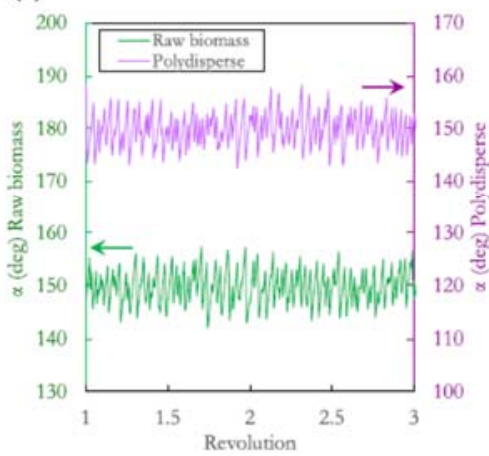

(b)

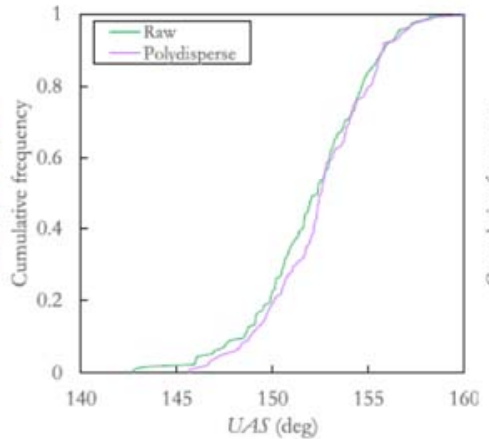

(c)

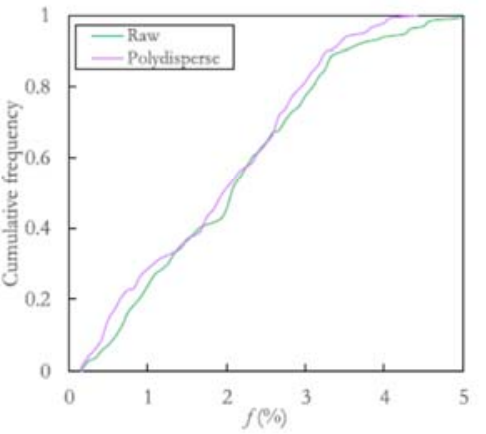

Figure 12. Comparison of DEM results between monodisperse raw biomass (100\% volume fraction at $d=746 \mu \mathrm{m})$ and a polydisperse sample (three particle sizes: $d=500,746$ and $890 \mu \mathrm{m}$ at 25, 50 and 25\% volume fractions, respectively). (a) Evolution of the $\alpha$ angle over time (for clarity, the $y$-axis of the data sets is not the same; e.g. the raw biomass results should be read on the left $y$-axis). (b) UAS cumulative distributions. (c). f cumulative distributions.

\section{CONCLUSIONS}

Rotating drum tests are pertinent for studying bulk flow of granular materials in a non-consolidated and dynamic conditioning. In this study, we evaluated the ability of DEM simulations for assessing flow behavior of raw and torrefied milled biomass in a rotating drum.

The challenging characteristics of biomass particles with respect to simulations (submillimetric size, elongated shape, cohesive nature) were integrated in a DEM model using a coarse-grained multisphere approach for shape representation, along with a cohesive SJKR contact model. Bulk measurements of the angle-of-repose, the bulk density and a retainment ratio were used for calibration of the interparticle coefficients of sliding friction, rolling friction and the Cohesion Energy Density.

Qualitative comparison with the experimental behavior in a rotating drum system made it possible to reduce the number of optimal sets of calibrated DEM parameters. To reproduce the experimental cohesive behavior, it was therefore necessary to select a set of optimum interparticle parameters among those with the highest cohesive energy density values. For raw biomass the optimal value of $C E D$ was ca. $50 \mathrm{~kJ} / \mathrm{m}^{3}$ while for torrefied powders CED values were higher and closer to the upper limit of tested values $\left(80 \mathrm{~kJ} / \mathrm{m}^{3}\right)$.

The selected parameters led to a realistic representation of the avalanche motion for the biomass materials that could be achieved through the combined effects of an elongated particle shape and interparticle cohesion. The calibrated DEM parameters obtained from relatively easy-to-implement bulk setups can therefore be used to reliably reproduce a dynamic non-consolidated flow of biomass particles, the latter being much more expensive to use as calibration setup in terms of computing time as stated in previous research. 
Overall, the granular flow dynamics was correctly captured by the DEM simulations. A continuous regime of flow developed for non-cohesive glass beads, while avalanches of particle clusters with centroid angle variations of up to $20^{\circ}$ were characteristic of biomass powders. Discrepancy between DEM results and the experimental values of the Upper Angle of stability remained under $7 \%$ and qualitatively similar distributions between experiments and simulations were obtained for the fraction of revolution to trigger events and size of avalanches. Although significant differences were found regarding the irregularity of the free-surface profile, similar numerical and experimental rankings of flowability could be established. This confirms the suitability of the DEM simulations for assessing flow of cohesive biomass particles in a freesurface dynamic system.

DEM simulations were useful to study the isolated effects of particle shape and cohesion on the flow behavior. An increase of $18 \%$ in the average centroid angle was observed when elongated particles were compared to spherical particles of the same equivalent size. This increase rises to ca. $+36 \%$ when a cohesive interaction $\left(50 \mathrm{~kJ} / \mathrm{m}^{3}\right)$ between particles is added.

While physical sound results were obtained using parameters calibrated using simple-to-implement bulk setups, the robustness of these parameters remains to be further clarified through, for example, the investigation of other flow conditions (including under consolidation). Future studies could also explore the effects of the particle-wall interaction parameters, polydispersity as well as more elaborate particle shape representations that are more favorable to particle interlocking.

\section{Acknowledgments}

The authors would like to gratefully acknowledge the support of the French Ministry of Higher Education and Research as well as the French-Dutch Network (Eole Scholarship) for their financial support. We are especially thankful to the French Council for Poplar (CNP) and the Huberlant sawmill (Cormicy, France) for kindly providing the raw wood used in this work.

\section{References}

[1] J. Dai, H. Cui, J.R. Grace, Biomass feeding for thermochemical reactors, Prog. Energy Combust. Sci. 38 (2012) 716-736. doi:10.1016/j.pecs.2012.04.002.

[2] Z. Guo, X. Chen, H. Liu, Q. Guo, X. Guo, H. Lu, Theoretical and experimental investigation on angle of repose of biomass-coal blends, Fuel. 116 (2014) 131-139. doi:10.1016/j.fuel.2013.07.098.

[3] M. Asadullah, Barriers of commercial power generation using biomass gasification gas: A review, Renew. Sustain. Energy Rev. 29 (2014) 201-215. doi:10.1016/j.rser.2013.08.074.

[4] J.S. Tumuluru, S. Sokhansanj, J.R. Hess, C.T. Wright, R.D. Boardman, A review on biomass torrefaction process and product properties for energy applications, Ind. Biotechnol. 7 (2011) 384 401. doi:10.1089/ind.2011.0014.

[5] W.H. Chen, J. Peng, X.T. Bi, A state-of-the-art review of biomass torrefaction, densification and applications, Renew. Sustain. Energy Rev. 44 (2015) 847-866. doi:10.1016/j.rser.2014.12.039.

[6] J. Pachón-Morales, J. Colin, F. Pierre, F. Puel, P. Perré, Effect of torrefaction intensity on the flow properties of lignocellulosic biomass powders, Biomass and Bioenergy. 120 301-312. doi:10.1016/j.biombioe.2018.11.017.

[7] G. Xu, M. Li, P. Lu, Experimental investigation on flow properties of different biomass and torrefied 
biomass powders, Biomass and Bioenergy. 122 (2019) 63-75. doi:10.1016/j.biombioe.2019.01.016.

[8] M.R. Wu, D.L. Schott, G. Lodewijks, Physical properties of solid biomass, Biomass and Bioenergy. 35 (2011) 2093-2105. doi:10.1016/j.biombioe.2011.02.020.

[9] F. Miccio, D. Barletta, M. Poletto, Flow properties and arching behavior of biomass particulate solids, Powder Technol. 235 (2013) 312-321. doi:10.1016/j.powtec.2012.10.047.

[10] F. Miccio, N. Silvestri, D. Barletta, M. Poletto, Characterization of woody biomass flowability, Chem. Eng. Trans. 24 (2011) 643-648. doi:10.3303/CET1124108.

[11] D. Barletta, R.J. Berry, S.H. Larsson, T.A. Lestander, M. Poletto, Á. Ramírez-Gómez, Assessment on bulk solids best practice techniques for flow characterization and storage/handling equipment design for biomass materials of different classes, Fuel Process. Technol. 138 (2015) 540-554. doi:10.1016/j.fuproc.2015.06.034.

[12] J. Falk, R.J. Berry, M. Broström, S.H. Larsson, Mass fl ow and variability in screw feeding of biomass powders - Relations to particle and bulk properties, Powder Technol. 276 (2015) 80-88. doi:10.1016/j.powtec.2015.02.023.

[13] M. Zulfiqar, B. Moghtaderi, T.F. Wall, Flow properties of biomass and coal blends, Fuel Process. Technol. 87 (2006) 281-288. doi:10.1016/j.fuproc.2004.10.007.

[14] R.G. Iacocca, R.M. German, The experimental evaluation of die compaction lubricants using deterministic chaos theory, Powder Technol. 102 (1999) 253-265. doi:10.1016/S00325910(98)00217-4.

[15] Y.L. Xiao, E. Specht, J. Mellmann, Experimental study of the lower and upper angles of repose of granular materials in rotating drums, Powder Technol. 154 (2005) 125-131. doi:10.1016/j.powtec.2005.04.040.

[16] J. Mellmann, The transverse motion of solids in rotating cylinders-forms of motion and transition behavior, Powder Technol. 118 (2001) 251-270. doi:10.1016/S0032-5910(00)00402-2.

[17] R. Li, H. Yang, G. Zheng, Q.C. Sun, Granular avalanches in slumping regime in a 2D rotating drum, Powder Technol. 326 (2018) 322-326. doi:10.1016/j.powtec.2017.12.032.

[18] H. Yang, G.L. Jiang, H.Y. Saw, C. Davies, M.J. Biggs, V. Zivkovic, Granular dynamics of cohesive powders in a rotating drum as revealed by speckle visibility spectroscopy and synchronous measurement of forces due to avalanching, Chem. Eng. Sci. 146 (2016) 1-9. doi:10.1016/j.ces.2016.02.023.

[19] V.R. Nalluri, M. Kuentz, Flowability characterisation of drug-excipient blends using a novel powder avalanching method, Eur. J. Pharm. Biopharm. 74 (2010) 388-396. doi:10.1016/j.ejpb.2009.09.010.

[20] A.W. Alexander, B. Chaudhuri, A. Faqih, F.J. Muzzio, C. Davies, M.S. Tomassone, Avalanching flow of cohesive powders, Powder Technol. 164 (2006) 13-21. doi:10.1016/j.powtec.2006.01.017.

[21] M.A.S. Quintanilla, J.M. Valverde, A. Castellanos, The transitional behaviour of avalanches in cohesive granular materials, J. Stat. Mech. Theory Exp. (2006). doi:10.1088/17425468/2006/07/P07015.

[22] S.C. Thakur, J.Y. Ooi, M.B. Wojtkowski, O.I. Imole, V. Magnanimo, H. Ahmadian, E.C. Montes, M. Ramaioli, Characterisation of cohesive powders for bulk handling and dem modelling, 3rd Int. Conf. Part. Methods Fundam. Appl. Part. 2013. (2013) 310-321. doi:10.1063/1.4812098. 
[23] V. Jaggi, M.C. Leaper, A. Ingham, Measuring the flow properties of small powder samples using an avalanche tester, Dry. Technol. 34 (2016) 723-728. doi:10.1080/07373937.2015.1072093.

[24] E. Emery, J. Oliver, T. Pugsley, J. Sharma, J. Zhou, Flowability of moist pharmaceutical powders, Powder Technol. 189 (2009) 409-415. doi:10.1016/j.powtec.2008.06.017.

[25] M. Wojtkowski, O.I. Imole, M. Ramaioli, E. Chaóvez Montes, S. Luding, Behavior of cohesive powder in rotating drums, AIP Conf. Proc. 1542 (2013) 983-986. doi:10.1063/1.4812098.

[26] P.A. Cundall, O.D.L. Strack, A discrete numerical model for granular assemblies, Géotechnique. 29 (1979) 47-65. doi:10.1680/geot.1979.29.1.47.

[27] Z. Hu, X. Liu, W. Wu, Study of the critical angles of granular material in rotary drums aimed for fast DEM model calibration, Powder Technol. 340 (2018) 563-569. doi:10.1016/j.powtec.2018.09.065.

[28] R.Y. Yang, R.P. Zou, A.B. Yu, Microdynamic analysis of particle flow in a horizontal rotating drum, Powder Technol. 130 (2003) 138-146. doi:10.1016/S0032-5910(02)00257-7.

[29] E. Alizadeh, F. Bertrand, J. Chaouki, Comparison of DEM Results and Lagrangian Experimental Data for the Flow and Mixing of Granules in a Rotating Drum, AIChE J. 60 (2014) 60-75. doi:10.1002/aic.14259.

[30] R.Y. Yang, A.B. Yu, L. McElroy, J. Bao, Numerical simulation of particle dynamics in different flow regimes in a rotating drum, Powder Technol. 188 (2008) 170-177. doi:10.1016/j.powtec.2008.04.081.

[31] H. Chen, Y.G. Xiao, Y.L. Liu, Y.S. Shi, Effect of Young's modulus on DEM results regarding transverse mixing of particles within a rotating drum, Powder Technol. (2017). doi:10.1016/j.powtec.2017.05.047.

[32] D.A. Santos, M.A.S. Barrozo, C.R. Duarte, F. Weigler, J. Mellmann, Investigation of particle dynamics in a rotary drum by means of experiments and numerical simulations using DEM, Adv. Powder Technol. 27 (2016) 692-703. doi:10.1016/j.apt.2016.02.027.

[33] C.M. Dury, G.H. Ristow, J.L. Moss, M. Nakagawa, Boundary effects on the angle of repose in rotating cylinders, Phys. Rev. E - Stat. Physics, Plasmas, Fluids, Relat. Interdiscip. Top. 57 (1998) 4491-4497. doi:10.1103/PhysRevE.57.4491.

[34] H.R. Norouzi, R. Zarghami, N. Mostoufi, Insights into the granular flow in rotating drums, Chem. Eng. Res. Des. 102 (2015) 12-25. doi:10.1016/j.cherd.2015.06.010.

[35] R.N. Cunha, K.G. Santos, R.N. Lima, C.R. Duarte, M.A.S. Barrozo, Repose angle of monoparticles and binary mixture: An experimental and simulation study, Powder Technol. 303 (2016) 203-211. doi:10.1016/j.powtec.2016.09.023.

[36] S.R. Mead, P.W. Cleary, G.K. Robinson, Characterising the failure and repose angles of irregularly shaped three-dimensional particles using DEM, Ninth Int. Conf. CFD Miner. Process Ind. CSIRO, Melbourne, Aust. (2012) 1-6.

[37] G.G. Pereira, S. Pucilowski, K. Liffman, P.W. Cleary, Streak patterns in binary granular media in a rotating drum, Appl. Math. Model. 35 (2011) 1638-1646. doi:10.1016/j.apm.2010.09.040.

[38] S.T. Nase, W.L. Vargas, A.A. Abatan, J.J. McCarthy, Discrete characterization tools for cohesive granular material, Powder Technol. 116 (2001) 214-223. doi:10.1016/S0032-5910(00)00398-3.

[39] D. Höhner, S. Wirtz, V. Scherer, A study on the influence of particle shape and shape approximation 
on particle mechanics in a rotating drum using the discrete element method, Powder Technol. 253 (2014) 256-265. doi:10.1016/j.powtec.2013.11.023.

[40] C.J. Coetzee, Particle upscaling: Calibration and validation of the discrete element method, Powder Technol. 344 (2019) 487-503. doi:10.1016/J.POWTEC.2018.12.022.

[41] Y.T. Feng, D.R.J. Owen, Discrete element modelling of large scale particle systems-I: exact scaling laws, Comput. Part. Mech. 1 (2014) 159-168. doi:10.1007/s40571-014-0010-y.

[42] A. Wachs, L. Girolami, G. Vinay, G. Ferrer, Grains3D, a flexible DEM approach for particles of arbitrary convex shape - Part I: Numerical model and validations, Powder Technol. 224 (2012) 374389. doi:10.1016/j.powtec.2012.03.023.

[43] M.W. Johnstone, Calibration of DEM models for granular materials using bulk physical tests, (2010). http://hdl.handle.net/1842/4655.

[44] M. Marigo, Discrete element method modelling of complex granular motion in mixing vessels: evaluation and validation, (2012) 1-341. http://core.kmi.open.ac.uk/download/pdf/8821055.pdf.

[45] M. Kodam, R. Bharadwaj, J. Curtis, B. Hancock, C. Wassgren, Cylindrical object contact detection for use in discrete element method simulations. Part I - Contact detection algorithms, (2010). doi:10.1016/j.ces.2010.08.006.

[46] B.K. Mishra, C. Thornton, D. Bhimji, A preliminary numerical investigation of agglomeration in a rotary drum, Miner. Eng. 15 (2002) 27-33. doi:10.1016/S0892-6875(01)00194-7.

[47] R. Brewster, G.S. Grest, A.J. Levine, Effects of cohesion on the surface angle and velocity profiles of granular material in a rotating drum, Phys. Rev. E - Stat. Nonlinear, Soft Matter Phys. 79 (2009) 1-7. doi:10.1103/PhysRevE.79.011305.

[48] M. Sebastian Escotet-Espinoza, C.J. Foster, M. Ierapetritou, Discrete Element Modeling (DEM) for mixing of cohesive solids in rotating cylinders, Powder Technol. 335 (2018) 124-136. doi:10.1016/j.powtec.2018.05.024.

[49] A.M. Faqih, B. Chaudhuri, A.W. Alexander, C. Davies, F.J. Muzzio, M. Silvina Tomassone, An experimental/computational approach for examining unconfined cohesive powder flow, Int. J. Pharm. 324 (2006) 116-127. doi:10.1016/j.ijpharm.2006.05.067.

[50] S. Just, G. Toschkoff, A. Funke, D. Djuric, G. Scharrer, J. Khinast, K. Knop, P. Kleinebudde, Experimental Analysis of Tablet Properties for Discrete Element Modeling of an Active Coating Process, AAPS PharmSciTech. 14 (2013) 402-411. doi:10.1208/s12249-013-9925-5.

[51] M. Combarros, H.J. Feise, H. Zetzener, A. Kwade, Segregation of particulate solids: Experiments and DEM simulations, Particuology. 12 (2014) 25-32. doi:10.1016/j.partic.2013.04.005.

[52] M. Marigo, E.H. Stitt, Discrete element method (DEM) for industrial applications: Comments on calibration and validation for the modelling of cylindrical pellets, KONA Powder Part. J. 32 (2015) 236-252. doi:10.14356/kona.2015016.

[53] T. Pöschel, C. Saluena, T. Schwager, Can we scale granular systems?, (2001).

[54] M. Sakai, S. Koshizuka, Large-scale discrete element modeling in pneumatic conveying, Chem. Eng. Sci. 64 (2009) 533-539. doi:10.1016/j.ces.2008.10.003.

[55] D.S. Nasato, C. Goniva, S. Pirker, C. Kloss, Coarse graining for large-scale DEM simulations of particle flow - An investigation on contact and cohesion models, Procedia Eng. 102 (2015) 1484- 
1490. doi:10.1016/j.proeng.2015.01.282.

[56] P.W. Cleary, M.L. Sawley, DEM modelling of industrial granular flows: 3D case studies and the effect of particle shape on hopper discharge, Appl. Math. Model. 26 (2002) 89-111. doi:10.1016/S0307-904X(01)00050-6.

[57] T. Roessler, A. Katterfeld, Scaling of the angle of repose test and its in fl uence on the calibration of DEM parameters using upscaled particles, Powder Technol. 330 (2018) 58-66. doi:10.1016/j.powtec.2018.01.044.

[58] S. Luding, M.M. Msm, Mesoscale modeling of particles and particles in fluids - Multi-Scale ( Models ) and - Continuum Theory (Applications ) - Jamming and un-jamming, (2013).

[59] J. Pachón-Morales, H. Do, J. Colin, F. Puel, P. Perré, D. Schott, DEM modelling for flow of cohesive lignocellulosic biomass powders: Model calibration using bulk tests, Adv. Powder Technol. (2019). doi:10.1016/j.apt.2019.01.003.

[60] J. Colin, Séchage en continu du bois énergie comme moyen de conditionnement en vue de sa conservation thermochimique : approches expérimentale et numérique, AgroParisTech, 2011. https://pastel.archives-ouvertes.fr/pastel-00861231.

[61] G. Almeida, D.V.B. Santos, P. Perré, Mild pyrolysis of fast-growing wood species (Caribbean pine and Rose gum): Dimensional changes predicted by the global mass loss, Biomass and Bioenergy. 70 (2014) 407-415. doi:10.1016/j.biombioe.2014.07.028.

[62] F. Pierre, G. Almeida, F. Huber, P. Jacquin, P. Perré, An original impact device for biomass characterisation: Results obtained for spruce and poplar at different moisture contents, Wood Sci. Technol. 47 (2013) 537-555. doi:10.1007/s00226-012-0512-9.

[63] J. Pachón-Morales, J. Colin, F. Pierre, T. Champavert, F. Puel, P. Perré, Flowability of lignocellusic biomass powders: Influence of torrefaction intensity, EPJ Web Conf. 140 (2017). doi:10.1051/epjconf/201714013017.

[64] T. Lichtenegger, S. Pirker, CFD-DEM modeling of strongly polydisperse particulate systems, Powder Technol. 325 (2018) 698-711. doi:10.1016/j.powtec.2017.11.058.

[65] Sympatec, QICPIC GmbH, (2018). https://www.sympatec.com/en/particlemeasurement/sensors/dynamic-image-analysis/qicpic/ (accessed July 11, 2018).

[66] J. Pachón-Morales, Torrefaction and grinding of lignocellulosic biomass for its thermochemical valorization : influence of pretreatment conditions on powder flow properties, Université ParisSaclay, 2019. http://www.theses.fr/2019SACLC051.

[67] P. Tegzes, T. Vicsek, P. Schiffer, Development of correlations in the dynamics of wet granular avalanches, Phys. Rev. E - Stat. Physics, Plasmas, Fluids, Relat. Interdiscip. Top. 67 (2003) 17. doi:10.1103/PhysRevE.67.051303.

[68] C. Kloss, C. Goniva, A. Hager, S. Amberger, S. Pirker, Models, algorithms and validation for opensource DEM and CFD-DEM, Prog. Comput. Fluid Dyn. An Int. J. 12 (2012) 140. doi:10.1504/PCFD.2012.047457.

[69] Q.J. Zheng, H.P. Zhu, A.B. Yu, Finite element analysis of the rolling friction of a viscous particle on a rigid plane, Powder Technol. 207 (2011) 401-406. doi:10.1016/j.powtec.2010.11.026.

[70] M. Obermayr, C. Vrettos, P. Eberhard, T. Däuwel, A discrete element model and its experimental 
validation for the prediction of draft forces in cohesive soil, J. Terramechanics. 53 (2014) 93-104. doi:10.1016/j.jterra.2014.04.003.

[71] K. Iwashita, M. Oda, Rolling Resistance at Contacts in Simulation of Shear Band Development by DEM, J. Eng. Mech. 124 (1998) 285-292. doi:10.1061/(ASCE)0733-9399(1998)124:3(285).

[72] K.L. Johnson, K. Kendall, A.D. Roberts, Surface Energy and the Contact of Elastic Solids, Proc. R. Soc. A Math. Phys. Eng. Sci. 324 (1971) 301-313. doi:10.1098/rspa.1971.0141.

[73] Z. Shen, M. Jiang, C. Thornton, DEM simulation of bonded granular material. Part I: Contact model and application to cemented sand, Comput. Geotech. 75 (2016) 192-209. doi:10.1016/j.compgeo.2016.02.007.

[74] S.C. Thakur, J.P. Morrissey, J. Sun, J.F. Chen, J.Y. Ooi, Micromechanical analysis of cohesive granular materials using the discrete element method with an adhesive elasto-plastic contact model, Granul. Matter. 16 (2014) 383-400. doi:10.1007/s10035-014-0506-4.

[75] GmbH DCS Computing, gran cohesion sjkr model — LIGGGHTS v3.X documentation, (n.d.). https://www.cfdem.com/media/DEM/docu/gran_cohesion_sjkr.html (accessed September 7, 2018).

[76] J.F. Favier, M.H. Abbaspour-Fard, M. Kremmer, Modeling nonspherical particles using multispheres, J. Eng. Mech. 127 (2001) 971-977.

[77] H. Kruggel-Emden, S. Rickelt, S. Wirtz, V. Scherer, A study on the validity of the multi-sphere Discrete Element Method, Powder Technol. 188 (2008) 153-165. doi:10.1016/j.powtec.2008.04.037.

[78] R. Maione, S. Kiesgen De Richter, G. Mauviel, G. Wild, DEM investigation of granular flow and binary mixture segregation in a rotating tumbler: Influence of particle shape and internal baffles, Powder Technol. 286 (2015) 732-739. doi:10.1016/j.powtec.2015.09.011.

[79] D. Markauskas, Á. Ramírez-Gómez, R. Kačianauskas, E. Zdancevičius, Maize grain shape approaches for DEM modelling, Comput. Electron. Agric. 118 (2015) 247-258. doi:10.1016/j.compag.2015.09.004.

[80] D. Markauskas, R. Kačianauskas, Investigation of rice grain flow by multi-sphere particle model with rolling resistance, Granul. Matter. 13 (2011) 143-148. doi:10.1007/s10035-010-0196-5.

[81] M. Rackl, F. Top, C.P. Molhoek, D.L. Schott, Biomass and Bioenergy Feeding system for wood chips : A DEM study to improve equipment performance, Biomass and Bioenergy. 98 (2017) 4352. doi:10.1016/j.biombioe.2017.01.003.

[82] H.Q. Do, A.M. Aragón, D.L. Schott, A calibration framework for discrete element model parameters using genetic algorithms, Adv. Powder Technol. (2018) 1-11. doi:10.1016/j.apt.2018.03.001.

[83] K. Deb, A. Pratap, S. Agarwal, T. Meyarivan, A fast and elitist multiobjective genetic algorithm: NSGA-II, IEEE Trans. Evol. Comput. 6 (2002) 182-197. doi:10.1109/4235.996017.

[84] J. Härtl, J.Y. Ooi, Numerical investigation of particle shape and particle friction on limiting bulk friction in direct shear tests and comparison with experiments, Powder Technol. 212 (2011) 231239. doi:10.1016/j.powtec.2011.05.022.

[85] Á. Ramírez-Gómez, E. Gallego, J.M. Fuentes, C. González-Montellano, F. Ayuga, Values for particle-scale properties of biomass briquettes made from agroforestry residues, Particuology. 12 
(2014) 100-106. doi:10.1016/j.partic.2013.05.007.

[86] D. Mateo-Ortiz, R. Méndez, Microdynamic analysis of particle flow in a confined space using DEM: The feed frame case, Adv. Powder Technol. 27 (2016) 1597-1606. doi:10.1016/j.apt.2016.05.023.

[87] M. Florian-Algarin, R. Mendez, Blend Uniformity and Powder Phenomena Inside the Continuous Tumble Mixer Using DEM Simulations, AIChE J. 61 (2015) 792-801. doi:10.1002/aic.14694.

[88] Y.T. Feng, K. Han, D.R.J. Owen, J. Loughran, On upscaling of discrete element models: Similarity principles, Eng. Comput. (Swansea, Wales). 26 (2009) 599-609. doi:10.1108/02644400910975405.

[89] W. Yang, Z. Zhou, D. Pinson, A. Yu, Periodic boundary conditions for discrete element method simulation of particle flow in cylindrical vessels, Ind. Eng. Chem. Res. 53 (2014) 8245-8256. doi:10.1021/ie404158e.

[90] X. Liu, Z. Hu, W. Wu, J. Zhan, F. Herz, E. Specht, DEM study on the surface mixing and whole mixing of granular materials in rotary drums, Powder Technol. 315 (2017) 438-444. doi:10.1016/j.powtec.2017.04.036.

[91] J. Pachón-Morales, J. Colin, J. Casalinho, P. Perré, F. Puel, Flowability characterization of torrefied biomass powders : static and dynamic testing Keywords :, Submitt. to Biomass Bioenergy. (2019) $1-31$. 